Portland State University

PDXScholar

1979

\title{
Stressful Life Events : a Comparative Study of Native American and Urban Samples
}

Sandra Ketcher

Portland State University

Follow this and additional works at: https://pdxscholar.library.pdx.edu/open_access_etds

Part of the Social Welfare Commons, and the Social Work Commons Let us know how access to this document benefits you.

\section{Recommended Citation}

Ketcher, Sandra, "Stressful Life Events : a Comparative Study of Native American and Urban Samples" (1979). Dissertations and Theses. Paper 2614.

https://doi.org/10.15760/etd.2610

This Thesis is brought to you for free and open access. It has been accepted for inclusion in Dissertations and Theses by an authorized administrator of PDXScholar. Please contact us if we can make this document more accessible: pdxscholar@pdx.edu. 
STRESSFUL LIFE EVENTS:

A COMPARATIVE STUDY OF NATIVE AMERICAN

AND URBAN SAMPLES

by

SANDRA KETCHER

A practicum submitted in partial fulfillment of the requirements for the degree of

MASTER

in

SOCIAL WORK

Portland State University

1979 
TO THE OFFICE OF GRADUATE STUDIES AND RESEARCH:

The advisor of the practicum approve the practicum of Sandra Coleen Ketcher presented March 26, 1979.

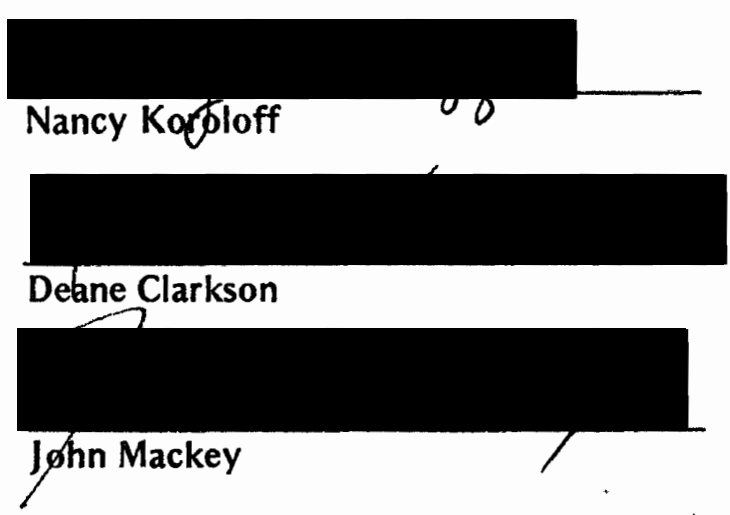




\section{ACKNOWLEDGEMENTS}

I wish to acknowledge my debt to Indian Health Service, Portland Area Office and the Yakima Indian Nation for their cooperation in the development of this study.

I also want to express my appreciation for the assistance and encouragement I have received from Dr. Delores Gregory, Dr. Deane Clarkson, Ms. Nancy Koroloff and John Mackey. Their reactions and thoughtful criticisms contributed much to this project.

I am particularly grateful to Ms. Agnes Cowen and her staff, Cherokee Bilingual Education Program, who carefully typed the final manuscript. 
TABLE OF CONTENTS

\section{PAGE}

ACKNOWLEDGEMENTS. ..............................

LIST OF TABLES. ........................... vi

\section{CHAPTER}

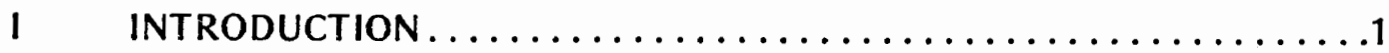

II LITERATURE REVIEW. ......................

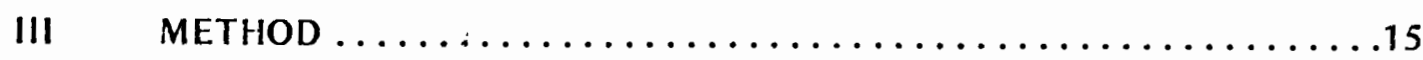

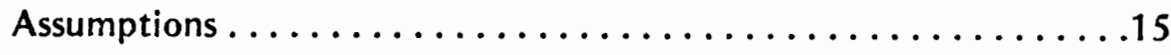

Questionnaire Development ..................... 15

The Study ............................. 19

Setting
Population
Pilot Study
Interviewers/Interview Training
Uata Collection

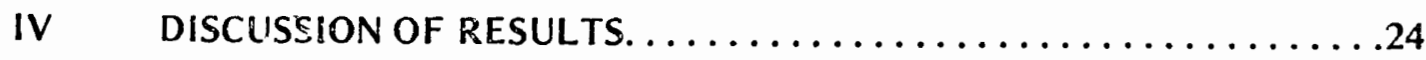

Equal and Sirrilar Ranking Order of Events ............25

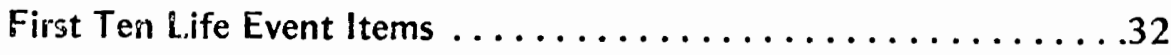

Rank Differences over Ten ........................

Grand Meani and Spread Differences ................... 38

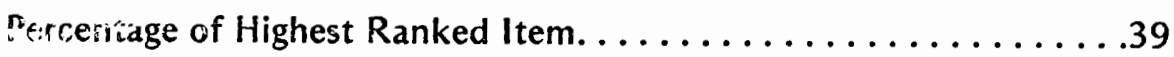

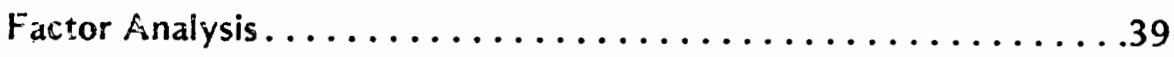

$\checkmark$ CONCLUSION ANID RECOMMENDATIONS..............44

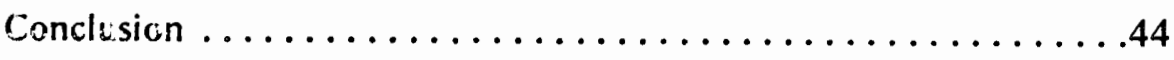

Fecommendation for Follow-Up................45 
PAGE

SELECTED REFERENCES $\ldots \ldots \ldots \ldots \ldots \ldots \ldots \ldots \ldots \ldots \ldots \ldots \ldots \ldots \ldots$

APPENDIX A................................ 49

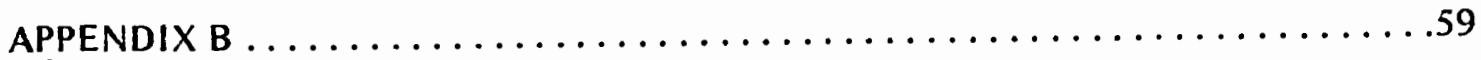

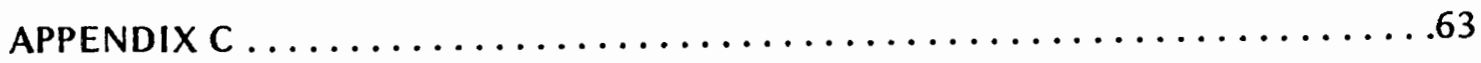

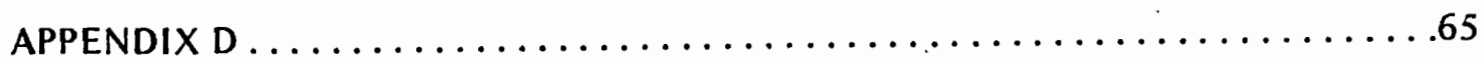




\section{LIST OF TABLES}

TABLE

PAGE

I Social Readjustment Rating Scale ................. 5

II SRRQ Item Mean Scores and Rank Order

for Miccosukee Sample .................. 8

8

III SRRQ Item Mean Scores and Rank Order

for Yakima Sample .................... 17

IV Revision of SRRQ Used in Yakima Groups.............. 20

V Item Mean Scores and Rank Order for Urban,

Miccosukee and Yakima Samples

VI Thirty-three Items Appearing on the Three

Questionnaires....................... 28

VII Rank Order of Similar Items of the Yakima,

Miccosukee and Urban Samples. ............... 30

VIII Equal or Similar Rank Order of Items................ 33

IX Items with Highest Differences in Rank

Between Samples. ..................... 36

$X \quad$ Percentage of Highest Ranked Item. ............... 40 


\section{CHAPTER I}

\section{INTRODUCTION}

In 1929, Walter Cannon, a professor of Psychology at Harvard University, published Bodily Changes in Pain, Anger, Fear and Rage. This classic text laid the groundwork for the position that our bodily organs are influenced by our emotions, by the way we feel and think. Cannon's book is considered a milestone in the history of physiology and psychosomatic medicine. Cannon described the effects of various emotional states on physiological functions and disease states (Lynch, 1977).

Cannon's treatise profoundly influenced the way men of modern medicine and psychology began to view human emotions. His treatise presented the position that human emotions significantly affect our physical and mental well-being (Lynch, 1977).

Equipped with Cannon's treatise, researchers began a series of studies which further suggested that sudden changes in one's individual life were often followed by the sudden onset of a variety of illnesses. Drs. Thomas Holmes and Richard Rahe, who explored this phenomenon intensively, developed a scale they called the "Life Change Index Scale" :

(Holmes and Rahe, 1968). A questionnaire, "Schedule of Recent Experiences," was developed at the University of Washington in Seattle in order to document systematically a: variety of life events that had preceded the onset of illness in patients. Realizing that although the original questionnaire had revealed connections between change in a person's life and the development of disease, it simply catalogued and gave each event equal weight or importance. Therefore, it was decided to ask a large group of individuals to rate a variety of life changes according to their importance (Lynch, 1977). 
Equipped with this new scale, the Social Readjustment Rating Scale, Holmes and Rahe began exploring a large number of different populations to measure life change events that occurred before the onset of disease (Lynch, 1977).

The Social Readjustment Rating Scale has been administered and standardized on a variety of cultures and subcultures in the past twelve years. Although various minority groups in the United States have been studied, one group remains virtually unknown (with the exception of one study) to the Social Readjustment Rating Scale; this group is the American Indian. In 1977, David Liberman, Ph.D., and Joel Frank administered a culturally modified version of the Social Readjustment Rating Scale to a selected sample of the Miccosukee tribe of Indians in Florida.

The subject of this paper is an extension of the work done by Holmes and Rahe on the development of the Social Readjustment Rating Scale or SRRS and of the study, "Individual Perception of Stressful Life Events; A Comparison of Native Americans, Rural, and Urban Samples," conducted by Dr. Liberman and Joel Frank. This study will compare those two samples with a sample of a selected Pacific Northwest Indian tribe served by an Indian Health Service facility.

The impetus for the project came from an expressed desire by the Indian Health Service at the Portland Area Office. Since most of the workload of mental health workers in the Indian Health Service is of the crisis intervention type, both short and long term planning for the entire service population is difficult because of the lack of sufficient data base. The utilization of the Mental and Social Services branch of the Indian Health Service, Yakima Service Unit, has increased dramatically over the past years. The Yakima tribal authorities have recognized these difficulties and have requested an assessment to assist them in their formulation plans for a comprehensive community mental health program. Consequently, the Yakima Reservation seemed an appropriate area to develop not only new services but to restructure existing ones in accordance with needs that may be identified (Gregory, 1978). 
"The Stressful Life Events: A Comparative Study of Native American and Urban Samples" study is a singular component of a total effort on the part of the Indian Health Service, Portland Area Office, to assess the probability and severity of functional impairment of the Indian people living on the Yakima Indian Reservation in the State of Washington, with the additional intent of facilitating planning and allocation.

This paper addresses the initial results of the author's study and the comparison of the results with the original Holmes and Rahe study and Liberman and Frank Native American study. 


\section{CHAPTER II}

\section{LITERATURE REVIEW}

The concept of stress or stressful life events has been the topic of many research efforts during the last decade. The most extensive work has been done by Thomas Holmes and Richard Rahe on the development of the Social Readjustment Rating Scale. An attempt will be made in this review to highlight studies utilizing the Social Readjustment Rating Scale. Various studies relating to stress or stressful life events will be briefly reviewed.

Holmes and Rahe (1967) utilized a sample of 394 individuals in the development of the Social Readjustment Rating Scale. The sample included 363 whites, 19 Blacks and 12 Orientals. The instrument consisted of 43 life event items empirically derived from clinical experience. Subjects were asked to rate a series of life events as to their relative degree of necessary readjustment. As a reference item, marriage was given an arbitrary value of 500 . Subjects scored the remaining events according to the magnitude of readjustment or change in one's customary pattern of life each necessitates. As compared to the reference item, items were scored on a 0-1000 scale. Table I depicts the rank order of the life event items which was derived when the mean score was divided by ten.

Liberman and Frank (1977) conducted a study on a randomly selected sample of 66 adult members of the Miccosukee Tribe of Indians of Florida. The sample of 66 individuals is approximately 15 percent of the tribal population. The Miccosukee Tribe resides in the Florida Everglades. The population of 637 people is widely dispersed along the Tamiami Trail between Miami and Noples. The major center is located forty miles west of Miami within the Everglades National Park. The tribe has retained its own language and culture to a great extent. It is a matriarchal, extended family society (Liberman and Frank, 1977). The Miccosukee sample received a culturally modified version of the Social Readjustment 
TABLE I

SOCIAL READJUSTMENT RATING SCALE

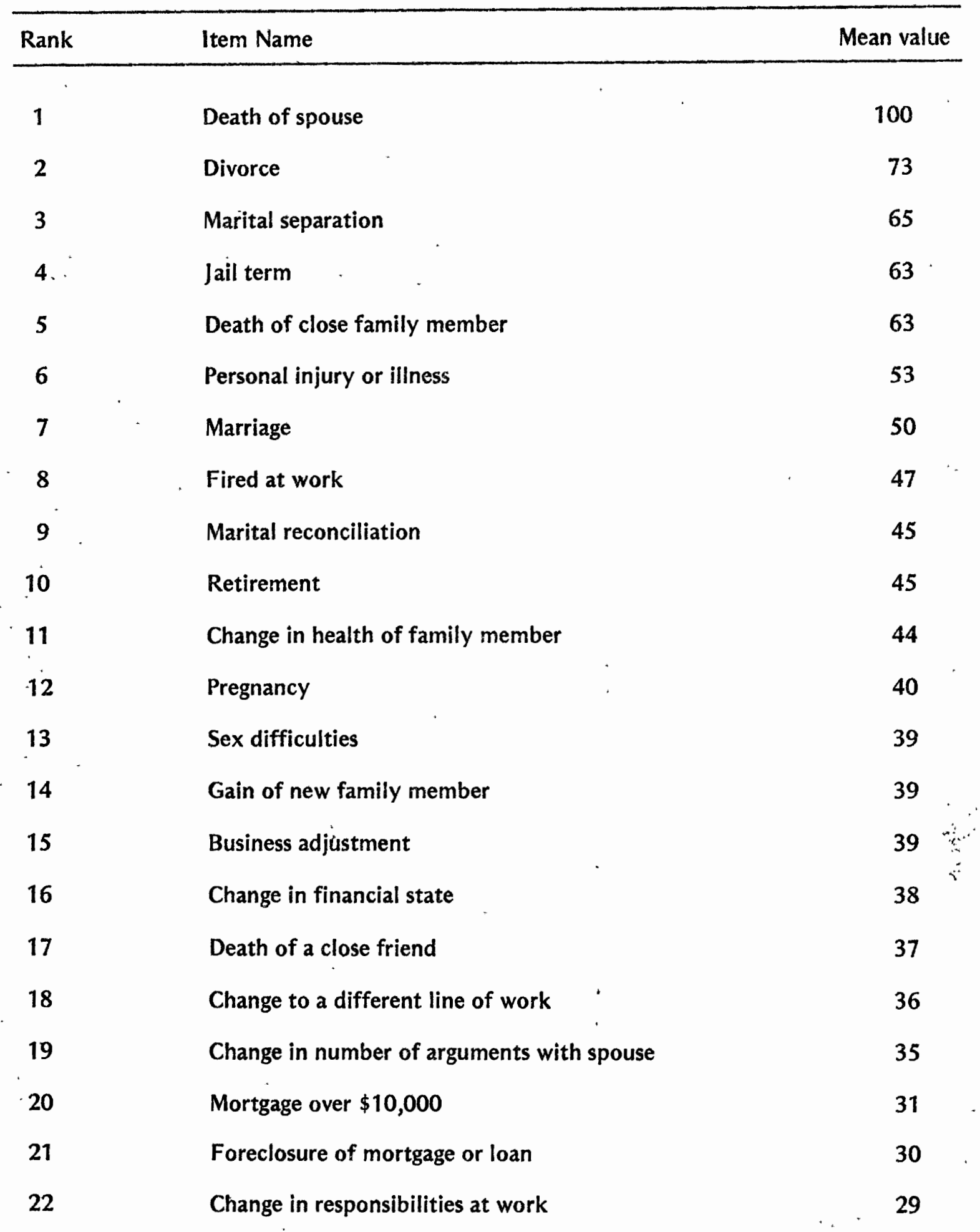


TABLE I (Continued)

Rank

23

24

25

26

27

28

29

30

31

32

33

34

35

36

37

38

39

40

41

42

43
Item Name

Son or daughter leaving home

Trouble with in-laws

29

Outstanding personal achievement

28

Wife begin or stop work

Begin or end school

Change in living conditions

Revision of personal habits

Trouble with boss

Change in work hours or conditions

Change in residence

Change in schools

Change in recreation

Change in church activities

19

Change in social activities

18

Mortgage or loan less than $\$ 10,000$

17

Change in sleeping habits

16

Change in number of family get-togethers

15

Change in eating habits

15

Vacation

13

Christmas

12

Minor violations of the law

29

26

26

25

24

23

20

20

20

19

9 8

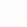

\section{5}


Rating Questionnaire which included four additional items particularly relevant to the community. They were: major change in your group of friends; moving to live in town; moving to a different reservation; and marriage to a non-Indian. The modified questionnaire was administered verbally in the Miccosukee language by interviewers trained by Liberman and Frank. Individuals were asked to rate each item on a scale from 0 to 20 in terms of the amount of "change" or "getting used to" it would cause in their lives. As a reference item "getting married" was assigned a rating of 10 . They were asked if each event would produce more or less change than marriage and then how much, more or less. A histogram scaled in units of one, from 0 to 20, was used as a visual aid in decision-making (Liberman and Frank, 1977). Rank order of the life event items, derived from the mean scores, is presented in Table II.

Holmes and associates (1967) applied the Social Readjustment Rating Questionnaire to two urban American subculture groups, urban Blacks and Mexican Americans. A questionnaire for quantifying the adjustment required by certain specified life change events was employed. The majority of life change items, the numerical responses of the two subculture groups and the responses of a previously examined white American middle-income group differed significantly. They found the responses of the two subculture groups differed more from the white American group. Despite these differences, Holmes and associates concluded population groups ranked the life-change items in a significantly concordant manner.

Prior to the comparative study of Blacks, Mexican American, and white American, Holmes and Masuda (1967) conducted a study on two Japanese samples of Hiroshima and Sendai. The data was collected from a modified version of the Social Readjustment Rating Questionnaire. The two groups were homogeneous in terms of relative order of ranking of the 43 item scores and the magnitude of the scores. Sendai males were found to differ in some respects from the other subgroups. The two samples were from an urban, university, and middle socioeconomic background. Holmes and Masuda compared the combined Japanese sample and a selected American sample. The data indicated essential similarities in their attitudes towards life events, but with some differences which reflected cultural variation. 


\section{TABLE \|}

SRRQ ITEM MEAN SCORES AND RANK ORDER FOR MICCOSUKEE SAMPLE

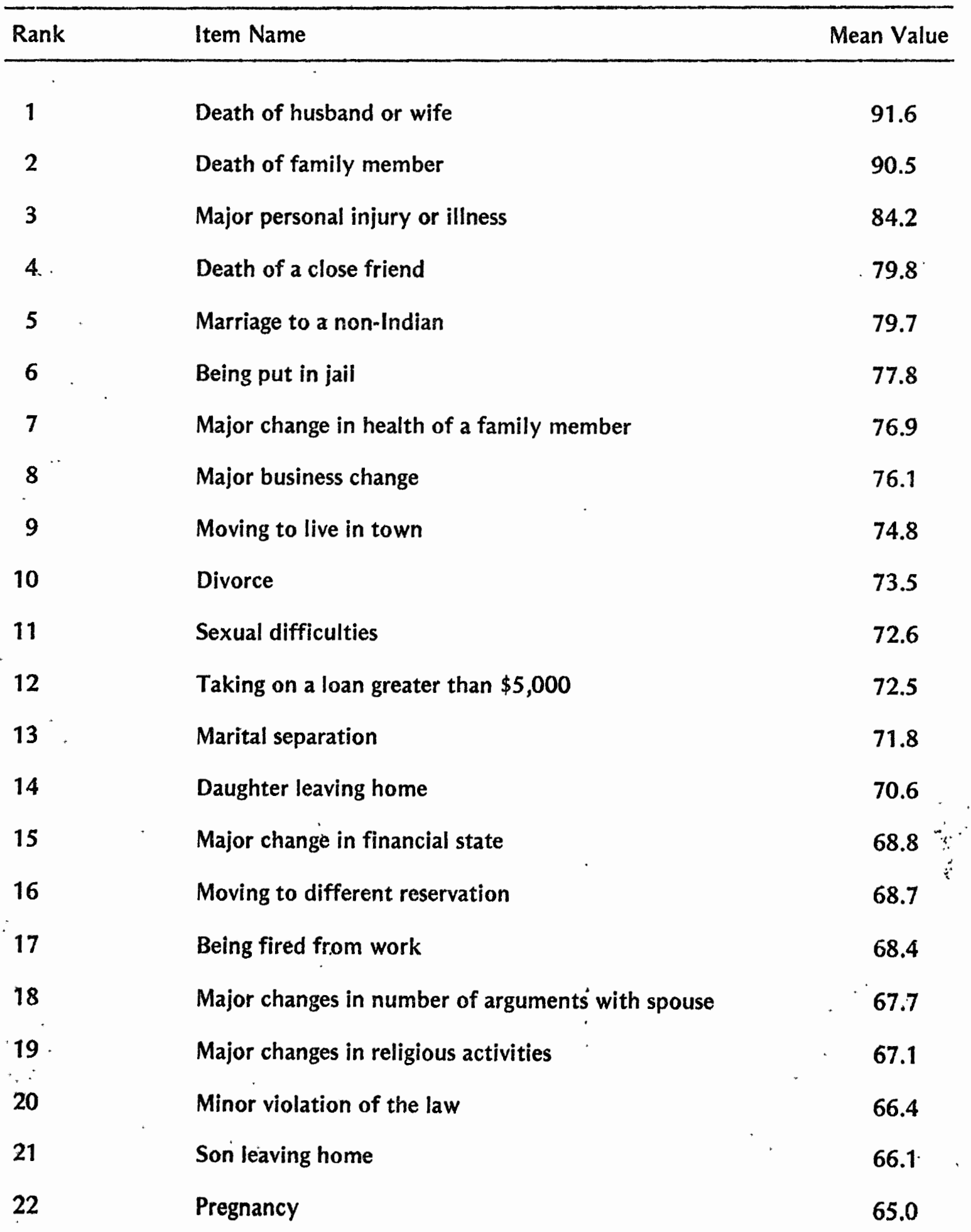


TABLE II (Continued)

Rank

Item Name

Mean Value

23

Major increase in responsibility at work

62.0

24

Spouse stopping work outside of home

61.6

25

Loss of anything you could not make payments on

61.4

26 .

Major change in social activities

61.4

27

Major change in number of faraily get-togethers

60.6

28

Gaining a new family member

58.9

29

Doing something of which you are very proud

58.8

30

Major change in working hours or condition

58.4

31

Major change in living conditions

58.3

32

Taking a loan of less than $\$ 5,000$

58.3

33

Stopping work because of old age

57.9

34

Change in place where you live

57.8

35

Major change in your group of friends

57.3

36

Major change in usual type or amount of recreation

57.0

37

Major decrease in responsibility at work

56.5

38

Change in personal habit

56.0

39

Change in eating habits

55.5

40

Change to a different kind of work

55.5

41

Major change in sleeping habits

54.5

42

Spouse starting work outside of home

54.3

43

Trouble with in-laws

Major change in eating habits

Beginning or stopping going to school

51.8

46

Marriage

50.0 
TABLE II (Continued)

\begin{tabular}{llc}
\hline Rank & Item Name & Mean Value \\
\hline 47 & Trouble with boss & 48.8 \\
48 & Christmas & 48.4 \\
49 & Vacation & 47.4 \\
50 & Changing to a new school & 47.3 \\
\hline
\end{tabular}


It was becoming apparent that there was a universal agreement concerning the relative significances of commonly experienced life change events. The Social Readjustment Rating Questionnaire was further administered to a French, Belgian, and Swiss sample via a French language translation by Harmon, Masuda, and Holmes (1969). A very high concordance between ail Europeans was observed. Holmes and associates compared a composite European sample with corresponding American sample. A high correlation of relative rank ordering of change required by life events was observed, but differences in culture and living conditions were reflected in the Social Readjustment Rating Scale obtained.

Rahe (1969) compared the results, life change items scales, in terms of their rank ordering of seven different cultural and American subculture groups. He concluded that despite many cross-cultural differences, similarities between the cultures were far more pronounced.

Rahe and associates (1970) administered a Swedish translation of the Social Readjustment Rating Questionnaire to two groups of Swedes living in Stockholm, a sample of university students and a sample of working, middle-aged men. Two comparative American samples were constructed from an American sample utilized in the original life changes scaling study. The Swedish samples were seen to uniformally give higher life change unit scores to most all the life event items than did the American sample. Rahe and associates concluded that in the majority of instances their mean scores were significantly higher than those given by the American sample. The rank order of the 43 life event items by the Swedish sample, however, was essentially the same as those of the Americans.

The relationship between the Social Readjustment Rating Scale and incidence of aid-seeking is examined in college population samples of different sizes by Bieliauskast and Strugar (1967). Reliability characteristics of a college-modified version of the Social Readjustment Rating Questionnaire were also studied. Their results generally suggested that the power of the Social Readjustment Rating Scale to discriminate aid-seeking from non aidseeking college students decreases as the size of the sample being tested decreases. 
A substantial amount of discussion has been devoted to the relationship between various life events and nearly simultaneous physical illnesses. Despite the amount of work, basic issues remain unclarified. A constant reoccurring theme is the question: how many of the life changes occurring around the time of an illness are really a result, rather than a cause, of the illness episode (Rahe and Arthur, 1967)?

In an attempt to shed light on this subject Rahe and Arthur (1967) conducted a survey on $\mathbf{3 0 0 0}$ members of the United States Navy. The sample completed a recent life changes and health status questionnaire. Life stress buildup prior to' illness onset was confirmed. A new finding was that life change data seen following illness experience was a reversed and nearly symmetrical picture of its counterpart prior to illness. According to Rahe and Arthur this data suggests that life changes precede or follow a wide variety of illnesses have equal validity.

Rahe and associates (1964) examined the relationship of environmental variables on the time of illness onset. Seven patient samples, representing five distinct medical entities and two control groups, were sampled using a standardized questionnaire yielding information about the quantity and timing of social stresses experienced over a ten-year period. The mounting frequency of changes in social status in the two years preceding disease onset was termed the psychosocial life crisis. It was postulated by Rahe and associates that the life crisis does represent change but does not necessarily precipitate major health changes.

Holmes (1977) conducted a series of studies to clarify the issue concerning the influence of emotions, psychosocial factors, and life changes on the onset and cause of disease. Holmes summarized the findings of the studies by concluding the more changes one has, the more likely one is to get sick. He continued by stating of those people with over 300 Life Change Units for a one-year period, almost 80 percent get sick in the near future. Individuals with 150 to 299 Life Change Units, about 50 percent get sick in the near future and with less than 150 Life Change Units, only about 30 percent get sick in the near future. 
Rahe and associates (1970) conducted a study on a non-hospital population to examine the relationship between social stress and subsequent recognition of illness. The study used virtually the entire complements aboard three United States Navy cruisers, 2664 men. The men completed a life changes questionnaire prior to a cruise of from six-to-elght months duration. Cruise period illness data was gathered on over 90 percent of those men sampled by the questionnaire. Rahe and associates perceived the results to indicate a low. order, positive relationship between crew members' pre-cruise life change intensity and their number of reported illnesses throughout their time at sea. The results appeared to support the notion of linear relationship between the subjects' life change unit magnitude and illness rate.

Grace and Grahan (1951) explored the issue of symptoms and disease occurring in settings of difficult life situations by focusing on an effort to correlate the occurrence of particular symptoms with particular situations. The survey included 128 out-patients. Twelve symptoms or diseases as responses to life situations was studied. It was found that each of the twelve conditions was associated with a particular, completely conscious attitude toward the precipitating situation.

Hinkle and associates (1957) conducted a study and the findings suggested that the determinants of general susceptibility to illness are both genetic and environmental. They concluded that the actual life situations encountered are less important than the way in which these situations are perceived. From their results, they found that the more frequently ill people perceive their life experiences as more challenging, demanding, and conflict-laden.

Masuda and Holmes (1977) utilized the data from two instruments, Social Readjustment Rating Scale and Schedule of Recent Experience, which were applied to nineteen studies to reveal the significant variability among groups in their perception of life events and their reports of the frequency of occurrence. Significant variables in either or both of these parameters were age, marital status, sex, socioeconomic status, ethnicity, level of 
education, culture, and experiencing of an event. Masuda and Holmes stated that these variables impose caution on investigations when relating life change to illness."

Minter and Kimball (1978) presented a review of investigations attempting to show correlation between life events and the onset of illness. They concluded by suggesting greater conitrols of the variables, sick role and the effect of stress upon illness behavior. It was further suggested that in future studies illness be more adequately documented than previously. They felt the data from the studies reviewed was not sufficiently sound to warrant any firm conclusions concerning the relationship between life events and illness onset.

Dohrenwend and Dohrenwend ("Psychiatric Disorders and Susceptibility to Stress: Reactions to Stress of Varying Magnitudes and Varying Origins") examined the extent to which psychopathology predisposes to stress by contrast with the extent to which stress predisposes to psychopathology. The paper examined the vulnerability and proneness of individuals to stressful life events. They concluded from their results that, to some extent, the stressful events accompanying psychopathology are a function of prior proneness on the part of the individuals involved. The findings from Dohrenwend and Dohrenwend's study and review of related research concluded that psychiatric patients are both more vulnerable and more prone than the general population. These individuals were seen as being victims of environmentally induced stressors to some extent. Beyond these conclusions other facts concerning the issue of casual or resultant relationship of stressful life events to onset of illness were unclear.

Existing studies have contributed greatly to the present understanding of the stress phenomenon. The findings of these studies suggested to the author an extension of the investigation of stress to a cross-cultural area. 


\title{
CHAPTER III
}

\author{
METHOD
}

\section{ASSUMPTIONS}

In general, a set of assumptions underlie any research or evaluation endeavor. The following statements were taken for granted in developing this study.

1. Individual cultures perceive life changes differently.

2. There is a consistency in the manner in which Native American groups perceive life changes.

3. The Native American groups perceive life changes as more stressful than an urban white American group.

\section{QUESTIONNAIRE DEVELOPMENT}

The instrument was developed around specific life event items derived from four sources: Social Readjustment Rating Questionnaire; culturally revised version of the SRRS developed by Liberman and Frank; Indian Health Service input; and Yakima Tribal input.

The Social Readjustment Rating Questionnaire was compiled from a series of studies on more than 5,000 patients which indicate the kinds of life events that tempor ally cluster about disease onset. A set of 43 items indicative of the life style or the kinds of events occurring in the individual's life were selected. They involve an adaptive response on the part of the persons affected and range from very'significant life events to those of a minor nature. The method for quantifying the social readjustment required by the 43 life events is derived from psychophysics. The item "marriage" was arbitrarily selected as the . module and given 500 points. The mean magnitude estimation for each life event signifies the mean amount of psychosocial readjustment required. The SRRS was derived from the 
mean scores obtained on the Social Readjustment Rating Questionnaire (Harmon, Masuda and Holmes, 1969).

The questionnaire administered to the Yakima sample consisted of a total of 47 life event items. Additions, deletions, and revisions were made upon the SRRQ in order to develop a questionnaire which would be culturally relevant to the Yakima sample. A list of the life event items are presented on Table III.

Written instructions were included with each questionnaire and individuals were given a verbal synopsis of the instructions. The verbal instructions were essentially as follows. Individuals were asked to rate a series of life events on a scale from 0 to 20 in terms of the amount of "change" or "getting used to" it would cause in their lives. Matriage was given a value of 10 . As the individuals completed each of the remaining events they were asked to think to themselves, "does this event require more or less change than marriage and then how much more or less change?" If they decided the event caused less change than marriage, they were asked to choose a number smaller than 10. A histogram scaled in units of one, from 0 to 20, was provided as a visual aid in decision-making (Liberman and Frank, 1977). A copy of the questionnaire appears in Appendix A.

The average time to administer the questionnaire was approximately thirty minutes. Individual demographic data was gained on a separate sheet from the questionnaire. Participants were asked to sign a consent form before beginning the questionnaire which was also removed from the questionnaire.

The wording of the original Social Readjustment Rating Questionnaire was simplified on certain items. Certain items were modified to allow for cultural differences. Questions were added that were determined culturally relevant to the Yakima sample. Original and revised items of the questionnaire and additions are shown on Table IV. 
TABLE III

SRRQ ITEM MEAN SCORES AND RANK ORDER FOR YAKIMA SAMPLE

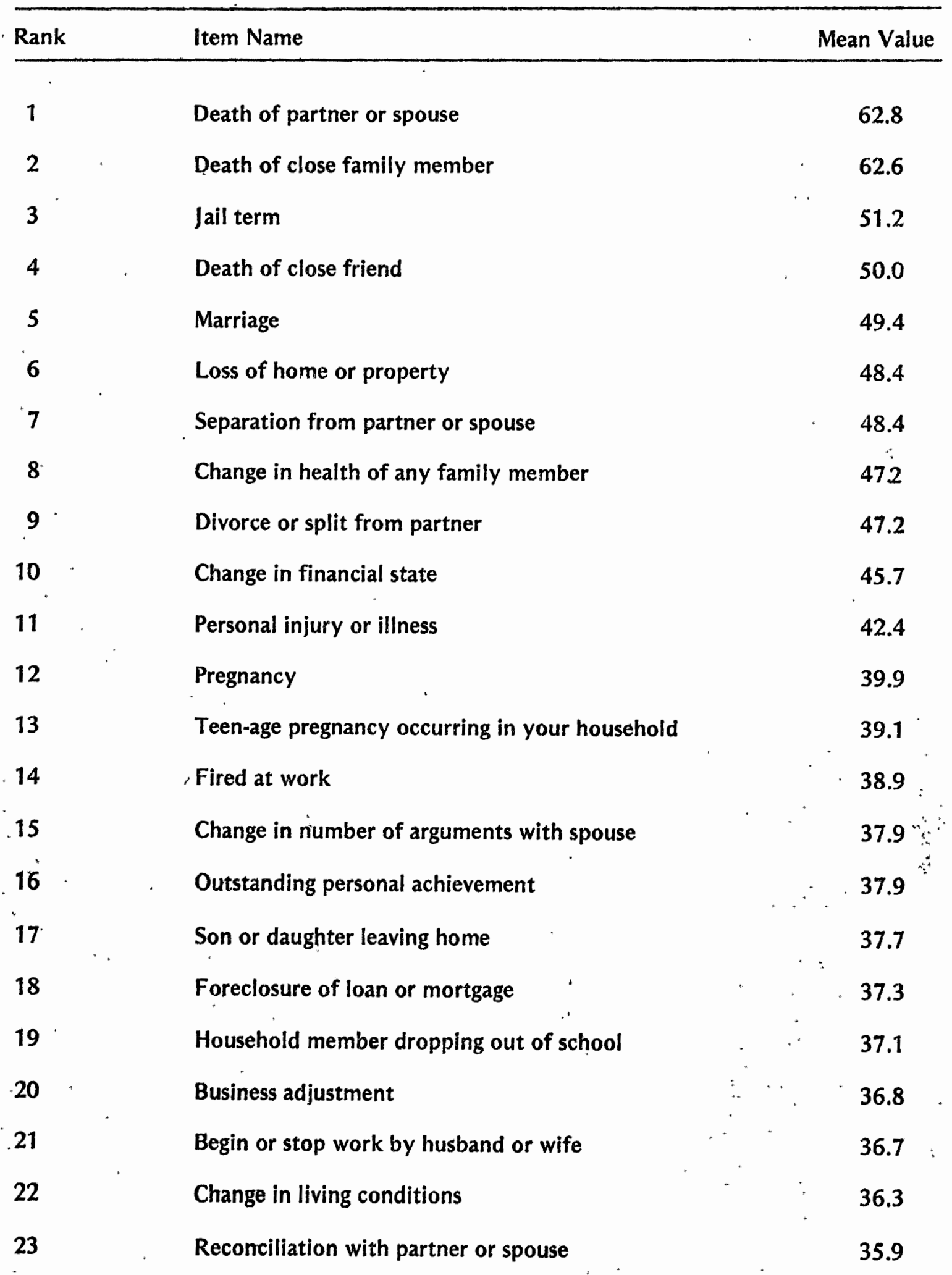


TABLE II (Continued)

Rank

Item Name

Mean Value

24

Gain of a new family member

34.6

25

Change in responsibilities at work

26

Retirement

33.0

27

Change in eating habits

33.0

28

Change in number of family get-togethers

32.9

29

Trouble with in-laws

30

Revision of personal habits

32.7

Change in residence

32.7

32

Sexual difficulties

31.2

33

Change in sleeping habits

30.9

Change to a different line of work

30.7

35

Change in work hours and conditions

30.2

36

Taking a short term loan

30.2

37

Minor violation of the law

29.4

38

39 .

Marriage to a non-Yakima occurring in your household

28.8

Change in social activities

28.5

40

Trouble with boss

28.1

$\cdot 41$

Vacation

28.0

42

Marriage to a male non-Indian occurring in your household

27.0

43

Begin or end school

26.9

44

Marriage to a female non-Indian occurring in your household

25.6

45

Change in church activities

25.1

46

Change in recreation

24.6

47

Change in schools

24.2 


\section{THE STUDY}

Setting

The Yakima Indian Reservation covers 1,563 square miles in southcentral Washington. Approximately 30,000 people live on the reservation; however only 6,500 are Indians. It is estimated that 1,000 Indians live within a twenty-mile radius of the reservation. The Yakima valley is a rich agricultural area and a large variety of crops are grown, including fruits and vegetables. Most of the farmers are non-Indian and much of the reservation land is either owned by them or leased to them. Much of the seasonal labor is done by a large migrant worker population. The reservation also has large range areas and some prime timberland (Indian Health Service Publication, 1977). The tribe is governed by a tribal council of fourteen elected members.

\section{Population}

The individuals for this study were a randomly selected sample of 105 Indians living on or near the Yakima Indian Reservation. This is approximately 1.4 percent of the population of Indians living on or near the reservation. Near indicates a twenty-mile radius of the reservation. The sample ranged in age from 18 to 85 years of age. The sample was represented by a 75 percent female population and a 25 percent male population. Selection of the sample population was from two sources: Indian Health Service records dating back five years and the 1977 Yakima tribal per capita rolls. All of the individuals. included in the tribal per capita rolls were enrolled members of the Yakima Tribe. Individuals selected from the Indian Health Service records were Indians but not of Yakima decent. Yakima Indians made up 95 percent of the total population.

Only those individuals 18 years old and older were selected for the sample. Those individuals from the random sample who had moved from the area or could not be located, or deceased were replaced. Those individuals refusing to participate were noted as such but 


\section{REVISION OF SRRQ USED IN YAKIMA GROUP}

\section{REVISIONS}

1. Original: Death of spouse

Revised: Death of partner or spouse

2. Original: Detention in jail

Revised: Jail term

3. Original: Marital separation from spouse

Revised: Separation from partner or spouse

4. Original: Major change in health of a family member

Revised: Change in health of any family member

5. Original: Major personal injury or illness

Revised: Personal injury or illness

6. Original: Divorce

Revised: Divorce or split from partner

7. Original: Major change in financial state

Revised: Change in financial state

8. Original: Being fired from work

Revised: Fired at work

9. Original: Major change in number of arguments with spouse

Revised: Change in number of arguments with spouse

10. Original: Major business adjustment

Revised: Business adjustment

11. Original: Wife beginning or ending work

Revised: Begin or stop work by husband or wife

12. Original: Major change in living conditions

Revised: Change in living conditions

13. Original: Marital reconciliation with spouse

Revised: Reconciliation with partner or spouse

14. Original: Major change in work responsibilities

Revised: Change in responsibilities at work

15. Original: Retirement from work

Revised: Retirement 
TABLE IV (Continued)

16. Original: Major change in eating habits Revised: Change in eating habits

17. Original: Major change in number of family get-togethers Revised: Change in number of family get-togethers

18. Original: Major change in sleeping habits Revised: Change in sleeping habits

19. Original: Major change in working conditions

Revised: Change in work hours or conditions

20. Original: Major change in social activities

Revised: Change in social activities

21. Original: Beginning or ending formal schooling

Revised: Begin or end school

22. Original: Major change in church activities

Revised: Change in church activities

23. Original: Major change in recreation

Revised: Change in recreation

24. Original: Changing to a new school

Revised: Change in school

\section{ADDITIONS}

25. Loss of home or property

26. Teen-age pregnancy occuring in your household

27. Household member dropping out of school

28. Taking a short term loan

29. Marriage to a non-Yakima occurring in your household

30. Marriage to a male non-Indian occurring in your household

31. Marriage to a female non-Indian occurring in your household

\section{DELETIONS}

32. Mortgage greater than $\$ 10,000$

33. Mortgage less than $\$ 10,000$ 
were not replaced in the sample. Ninety-four of the 105 individuals selected for the study completed a questionnaire. A 90 percent response rate was achieved by the study.

\section{Pilot Study}

The pilot sample consisted of ten Native Americans. The sample of ten were contacted for the most part while attending the Yakima Indian Health Service Unit. In spite of the unorthodox method, good proportions of male, female, Yakima and other tribal affiliation groups were obtained.

\section{Interviewers/Interview Training}

The questionnaire was administered verbally to the Yakima sample by three Portland State University Social Work students, two undergraduates and the author, and six Yakima tribal members. The questionnaire was administered in the Yakima language to those individuals of the sample who spoke only the Yakima language by interviewers fluent in the Yakima language.

Interviewers were involved in a twelve-hour training session in survey interviewing. Use was made of a video tape developed by Linda Ater, University of Oregon Health Science Center, Illustrating techniques of interviewing. The training session focused as a guide for persons without previous training or experience in interviewing. Interviewers were acquainted with the basic fundamentals and techniques of interviewing. An outline of the training material developed by Ms. Ater can be found in Appendix B.

\section{Data Collection}

Approximately two weeks prior to the actual interviewing, letters were sent to the participants. The letter was sent under the auspices of the Indian Health Service, Portland Area Office, and the Yakima Tribal Council. The letter states 300 people were selected to participate in the study. The author's study is a single component of a total effort on the part of the Indian Health Service, Portland Area Office; therefore, only a selected random 
sample was utilized of the total 300 -selected. The letter explained to the individuals how they were selected as participants, why the study was being conducted, and it urged their cooperation. The letter further explained that an interviewer would be meeting them at their homes in approximately two weeks. A copy of the letter can be found in Appendix C.

Participants were asked to sign a consent form which was witnessed by the interviewer and removed from the questionnaire. A demographic data sheet was completed before beginning the questionnaire. The demographic data sheet was also removed from the questionnaire. Individuals were given a verbal synopsis of the instructions before beginning the questionnaire. Interviewers read each life event item aloud to the individual and circled their responses. Upon completion of the questionnaire it was placed in a separate envelope from the consent form and data sheet and returned by the interviewers to the Yakima Service Unit. 


\section{CHAPTER IV}

\section{DISCUSSION OF RESULTS}

It should be mentioned at this point that there is a discrepanoy among the three samples. "Marriage" was given an arbitrary value by each of the three sampless. The urban sample, the originat study conducted by Holmes and Rahe, assigned the value of 500 and the Miccosukee sample assigned the value of 10. In examining the results 20 of the 94 participants assigned a different value to "marriage" than 10. This fact will be taken into consideration in the discussion of the results.

The data was converted to a $0-1000$ scale to facilitate comparison of the three samples. Table $V$ illustrates the rank order of life event items derived from the mean scores of the three samples. A dash indicates items not utilized by that sample. There were 33 comparable items from the Yakima, Miccosukee and urban samples. The 33 items which appeared on all three of the samples is depicted on Table VI. The life event items are ranked according to mean scores. There were six categories of similar life event items but because of wordage differences from one sample to another they were not considered comparable items. The similar items and their rank order are noted on Table VII.

\section{EQUAL AND SIMILAR RANKING ORDER OF EVENTS}

There were three items with equal rank order in the Yakima and Miccosukee samples. "Death of spouse or partner" was given the rank order of 1. "Death of a close family member" was ranked 2 by both samples and "death of a close friend" was ranked 4 . These life event items focus on the actual termination of an interpersonal relationship. The findings reflect a cultural group orientation. The significance of the high ranking and equal ranking of the events reinforce the extended family concept among Native Američan people. The 
TABLE V

RANK ORDER FOR
URBAN, MICCOSUKEE AND YAKIMA SAMPLES

\begin{tabular}{|c|c|c|c|}
\hline Item Name & Yakima & Miccosukee & Urban \\
\hline Death of partner or spouse & 1 & 1 & 1 \\
\hline Death of close family member & 2 & 2 & 5 \\
\hline Jail term & 3 & 6 & 4 \\
\hline Death of a close friend & 4 & 4 & 17 \\
\hline Marriage & 5 & 46 & 7 \\
\hline Loss of home or property & 6 & - & - \\
\hline Separation from partner or spouse & 7 & 13 & 3 \\
\hline Change in health of any farnily member & 8 & 7 & 11 \\
\hline Divorce or split from partner & 9 & 10 & 2 \\
\hline Change in financial state & 10 & 15 & 16 \\
\hline Personal Injury or illness & 11 & 3 & 6 \\
\hline Pregnancy & 12 & 22 & 12 \\
\hline Teen-age pregnancy occurring in your household & 13 & - & - \\
\hline Fired at work & 14 & - & 8 \\
\hline Change in number of arguments with spouse & 15 & 18 & 19 \\
\hline Outstanding personal achievement & 16 & 29 & 25 \\
\hline Son or daughter leaving home & 17 & - & 23 \\
\hline Foreclosure of loan or mortgage & 18 & - & 21 \\
\hline Household member dropping out of school & 19 & - & - \\
\hline Business adjustment & 20 & 8 & 15 \\
\hline Begin or stop work by husband or wife & 21 & - & - \\
\hline
\end{tabular}


TABLE V (Continued)

Item Name

Yakima

Miccosukee

Urban

Change in living conditions

22

31

28

Reconciliation with partner or spouse

23

-

9

Gain of new family member

24

Change in responsibilities at work

25

-

22

Retirement

33

10

Change in eating habits

27

44

40

Change in number of family get-togethers

Trouble with in-laws

Revision of personal habits

Change in residence

Sexual difficulties

11

Change in sleeping habits

41

Change to a different line of work

Change in work hours and conditions

Taking a short term loan

Minor violation of law

Marriage to a non-Yakima occurring in your household

Change in social activities

Trouble with boss

Vacation

Marriage to male non-Indian occurring in your household

Begin or end school

Marriage to female non-Indian occurring in your household 
TABLE V (Continued)

\begin{tabular}{|c|c|c|c|}
\hline Item Name & Yakima & Miccosukee & Urban \\
\hline Change in church activities & 45 & 19 & 35 \\
\hline Change in recreation & 46 & 36 & 34 \\
\hline Change in schools & 47 & 50 & 33 \\
\hline Christmas & - & 48 & 42 \\
\hline Daughter leaving home & - & 14 & - \\
\hline Son leaving home & - & 20 & - \\
\hline Loss of anything you could not make payments on & - & 25.5 & - \\
\hline Wife begin or stop work & - & - & 26 \\
\hline Spouse stopping work outside of home & - & 24 & - \\
\hline Spouse starting work outside of home & - & 42 & - \\
\hline Major increase in responsibilities at work & - & 23 & - \\
\hline Taking on a loan greater than $\$ 5,000$ & - & 12 & - \\
\hline Taking on a loan less than $\$ 5,000$ & - & 32 & - \\
\hline Mortgage over $\$ 10,000$ & - & - & 20 \\
\hline Mortgage or loan less than $\$ 10,000$ & - & - & 37 \\
\hline Marriage to a non-Indian & - & 5 & - \\
\hline Moving to live in town & - & 9 & - \\
\hline Moving to a different reservation & - & 16 & - \\
\hline Major change in your group of friends & · & 35 & - \\
\hline
\end{tabular}


TABLE VI

THIRTY-THREE ITEMS APPEARING ON ALL THREE QUESTIONNAIRES

Item Name

Yakima Miccosukee

Urban

Death of partner or spouse 1

Death of close family member

2

Jail term

3

Death of close friend

4

Marriage

5

Separation from partner or spouse

7

Change in health of any family member

8

9

10

11

12

15

16

20

Business adjustment

- 22

Change in living conditions 24

Gain of new family member

24

Retirement

26

Change in eating habits

Sexual difficulties

1

2

6

4

46

13

7

10

15

3

22

18

29

25

15

Change in number of family get-togethers

Trouble with in-laws

Change in residence 
TABLE VI (Continued)

Item Name

Yakima

Miccosukee

Urban

Change in sleeping habits

33

41

38

Change to a different line of work

34

40

18

Change in work hours and conditions

35

30

31

Minor violation of law

37

20

43

Change in social activities

39

25.5

36

Trouble with boss

40

47

30

Vacation

41

49

41

Begin or end school

43

45

27

Change in church activities

45

19

35

Change in recreation

46

36

34

Change in schools

47.

50

33 
TABLE VII

RANK ORDER OF SIMILAR ITEMS OF THE YAKIMA, MICCOSUKEE AND URBAN SAMPLES

\begin{tabular}{|c|c|c|c|}
\hline Item Name & Yakima & Miccosukee & Urban \\
\hline Son or daughter leaving home & 17 & - & 23 \\
\hline Daughter leaving home & - & 14 & - \\
\hline Son leaving home & 一 & 20 & - \\
\hline Foreclosure of loan or mortgage & 18 & - & 21 \\
\hline Loss of anything you could not make payments on & - & 25.5 & - \\
\hline Begin or stop work by husband or wife & 21 & - & - \\
\hline Wife begin or stop work & - & - & 26 \\
\hline Spouse stopping work outside of home & - & 24 & - \\
\hline Spouse starting work outside of home & - & 42 & - \\
\hline Change in responsibilities at work & 5 & - & 22 \\
\hline Major increase in responsibilities & - & 23 & - \\
\hline Taking a short term loan & 36 & - & - \\
\hline Taking on a loan greater than $\$ 5,000$ & - & 12 & - \\
\hline Taking a loan less than $\$ 5,000$ & - & 32 & - \\
\hline Mortgage over $\$ 10,000$ & - & - & 20 \\
\hline Mortgage or loan less than $\$ 10,000$ & - & - & 37 \\
\hline $\begin{array}{l}\text { Marriage to a male non-Indian occurring in your } \\
\text { household }\end{array}$ & .42 & - & - \\
\hline $\begin{array}{l}\text { Marriage to female non-Indian occurring in your } \\
\text { household }\end{array}$ & 44 & - & - \\
\hline Marriage to a non-Indian & - & 5 & - \\
\hline $\begin{array}{l}\text { Marriage to a non-Yakima occurring in your } \\
\text { household }\end{array}$ & 38 & - & - \\
\hline
\end{tabular}


extended family concept might not appear with such significance had the study been conducted on a Native American non-reservation group. Reservation life contributes to the close living of the population and reinforcement of cultural values.

Inspection of items with similar rank order between the Yakima and Miccusokee samples revealed two items with ranking differences of 1. On theYakima sample "change in health of any family member" received the rank order of 8 . On the Miccosukee sample this item received the rank order of 7. "Divorce or split from partner" was ranked 9 on the Yakima sample and 10 on the Miccosukee sample. These items focus on the actual or threatened termination of an interpersonal relationship.

There is a consistency in the responses between the two Native American groups to life event items relating to a family and friends. The findings reflect a cultural group orientation.

There were three items with equal ranking order between the Yakima and urban sample. "Death of a partner or spouse" was ranked 1 out of the 43 items. The Miccosukee sample ranked this life event item 1 out of 50 items, as did the majority of other samples administered the Social Readjustment Rating Questionnaire. The actual termination of an interpersonal relationship was the most stressful of the 33 comparable life event items for all three samples. "Pregnancy" was ranked 12 on the Yakima and on the urban sample. "Vacation" ranked 41 on both samples. Two items involved similar ranking order between the Yakima and urban sample. "Jail term" was ranked 3 on the Yakima and 4 on the urban sample. "Change in residence" was ranked 31 on the Yakima sample and 32 on the urban sample. The life event items were related to changes in group affiliation and peer relations. It is unclear whether they indicate an incorporation into the "white" society on the part of the Yakima sample.

Table VIII represents those items with equal and similar rank order of the Yakima and Miccosukee samples, and the related urban rank order of those particular life event 
items. Table VIII also represents equal and similar rank order of the Yakima and urban samples, and the related Miccosukee rank order of those particular life event items.

\section{FIRST TEN LIFE EVENT ITEMS}

Inspection of the ten highest ranked events for the Yakima sample revealed three life event items involved death and one concerned major change in health, a related area. Added to these four are "divorce or split from partner or spouse" and "separation from partner or spouse." The six life event items focus on the actual or threatened termination of an interpersonal relationship (Liberman and Frank, 1977). Two of the remaining four events, "marriage" and "jail term," may relate to changes in group affiliation and peer relations. The remaining two events, "change in financial state" and "loss of home or property," are related to changes affecting one's economic well-being. The significance of the two events may be related to the poverty level in which many Native Americans exist. The higher rank order given to these items may reflect a heightened strain for the Yakima sample when the securities of life are threatened. Loss of land is a century old issue with the Native American people. This issue could be considered when explaining the higher rank of "loss of home or property." This issue is particularly relevant to the Yakima Indians since the majority of prime acreage on the Yakima Indian Reservation is owned or leased by non-Indians. Also, there is an influx of migrant workers on the reservation during the spring and summer seasons for the harvesting of crops.

The three groups agreed on four of the 33 life event items as ranking in the first

ten. These four were "death of partner or spouse," "death of a family member," "jail term," and "divorce." Items ranked in the first ten by the urban sample, primarily a white American group, but not by either of the Native American groups were "fired at work," "retirement," and "marital reconciliation." On the other hand, only the Native American groups ranked the items "death of a close friend" and "change in health of a family member" in the first ten. 
TABLE VIII

EQUAL OR SIMILAR RANK ORDER OF ITEMS

YAKIMA AND MICCOSUKEE SAMPLES

\begin{tabular}{lccc}
\hline Item Name & Yakima & Miccosukee & Urban \\
\hline Death of partner or spouse & 1 & 1 & 1 \\
Death of close family member & 2 & 2 & 5 \\
Death of close friend & 4 & 4 & 17 \\
Change in health of any family member & 8 & 7 & 11 \\
Divorce or split from partner & 9 & 10 & 2 \\
\hline
\end{tabular}

YAKIMA AND URBAN SAMPLES

\begin{tabular}{lrrr}
\hline Item Name & Yakima & Urban & Miccosukee \\
\hline Death of partner or spouse & 1 & 1 & 1 \\
Pregnancy & 12 & 12 & 22 \\
Vacation & 41 & 41 & 49 \\
Jail term & 3 & 4 & 6 \\
Change in residence & 31 & 32 & 34 \\
\hline
\end{tabular}


Two of the life event items ranked in the first ten only by the urban sample, "fired at work" and "retirement," appear related to a cultural difference between the urban and Native American samples. Perhaps, there is a manifestation of some degree of financial security provided to the Native American groups by tribal membership through per capita payments and tribal programs. Also, there is a sense of security provided through group affiliation. The concept of retirement was unknown in the Indian culture until very recently (Liberman and Frank, 1977). "Marital reconciliation" was perceived as producing less change by the Native American samples.

Both Native American groups ranked the life event items "death of a close friend" and "change in health of a family member" in the first ten life event items in comparison to the urban sample. The fact that the Native American groups regarded these items as requiring more adjustment than did the urban sample tends to reinforce the concept that Native Americans have a close family network.

\section{RANK DIFFERENCES OVER TEN}

In order to further examine the differences in perception, the events with the greatest rank differences from the rating scores given by the Yakima sample were compared to the rating scores given by the urban and Miccosukee samples. Items with a ranking difference over ten were compared. Table IX illustrates these life event items.

Eleven life event items had rank differences of over ten when the Yakima and Miccosukee samples were compared. The Yakima sample ranked "marriage," "change in eating habits," "trouble with in-laws," "outstanding personal achievement," and "pregnancy" as more stressful than did the Miccosukee sample. The Miccosukee sample ranked "sexual difficulties," "minor violation of the law," "change in church activities," "change in social activities," "business adjustment," and "change in recreation" as more stressful changes than did the Yakima sample. Three of the six stressful life events for the Miccosukee sample are related to social exchange. This difference in perception may be related to 
traditionalism. The Miccosukee Tribe is considered to be a progressive and traditional Indian society. In truth and actuality their traditionalism is expressed through the following: they actively practice and use Indian medicine; the first language of 90 percent of the tribe is the Miccosukee language; and Indian children attend a tribal Indian school on the reservation (Liberman, 1979). They were noted by Liberman and Frank as being a grouporientated society. Considering the Miccosukee Tribe as a traditional group-orientated society it is understandable that emphasis would be placed on group activities. The population is widely dispersed among the reservation area which would imply some isolation of tribal members but not extensive. This would again reinforce the importance of group activities. The Yakima Tribe is a much larger tribe with less isolation among tribal members. Located on the Yakima Indian Reservation are three communities which provide the opportunity for meeting commercial needs and informal social contact.

In comparison to the urban sample, the Yakima sample found "death of a close friend," "change in the number of family get-togethers," and "change in eating habits" more stressful life event items. The concern over the death of a close friend reflects the extended family concept among Native Americans and relates to their group orientation. The rank order of the two events again relate to cultural differences between the urban and the Native American sample. Upon examining items of the Miccosukee and urban sample, "death of a close friend" and "family get-togethers" were also noted as items relatively more stressful to the Miccosukee sample.

Items perceived as producing less change by the Yakima sample were "sexual difficulties," "change to a different line of work," "begin or end school," "retirement," "change in schools," "change in recreation," "trouble with boss," and "change in church activities." Three of the life event items refer to or are related to labor. The diversity appears to reflect cultural differences between the urban and Yakima sample. The concept of "retirement" was unknown in the Indian culture until recently (Liberman and Frank, 1977). "Begin or end school" and "change schools" could reflect the Yakima sample's 
TABLE IX

ITEMS WITH GREATEST DIFFERENCE IN RANK BETWEEN SAMPLES

YAKIMA AND MICCOSUKEE SAMPLES

\begin{tabular}{lccc}
\hline Item Name & Yakima & Miccosukee & Difference \\
\hline Marriage* & 5 & 46 & -41 \\
Sexual difficulties & 32 & 11 & 21 \\
Change in eating habits* & 27 & 44 & -17 \\
Minor violation of law & 37 & 20 & 17 \\
Change in church activities & 45 & 19 & 16 \\
Trouble with in-laws* & 29 & 43 & -14 \\
Change in social activities & 39 & 25.5 & 13.5 \\
Outstanding personal achievement* & 16 & 29 & -13 \\
Business adjustment & 20 & 8 & 12 \\
Pregnancy* & 12 & 22 & -10 \\
Change in recreation & 46 & 36 & 10 \\
\hline
\end{tabular}

YAKIMA AND URBAN SAMPLES

\begin{tabular}{llll}
\hline Item Name & Yakima & Urban & Difference \\
\hline
\end{tabular}

Sexual difficulties

32

13

19

Change to a different line of work

34

18

16

Begin or end school

43

27

16

Retirement

26

10

16

Change in schools

47

33

14 
TABLE IX (Continued)

\begin{tabular}{lccc}
\hline Item Name & Yakima & Urban & Difference \\
\hline Death of a close friend* & 4 & 17 & -13 \\
Change in eating habits* & 27 & 40 & -13 \\
Change in recreation & 46 & 34 & 12 \\
Change in number of family get-togethers* & 8 & 39 & -11 \\
Trouble with boss & 40 & 30 & 10 \\
Change in church activities & 45 & 35 & 10 \\
\hline
\end{tabular}

*Relatively more stressful to the Yakima sample. 
lack of concern for school; in contrast, however, the life event item "household member dropping out of school," exclusive to the Yakima sample, was ranked 17 out of the 47 items on the Yakima sample.

The low ranking for the item "sexual difficulties" could be an expression of an unwillingness from the sample to reveal personal data. This item received a higher ranking on both of the other samples. The significance of the low ranking of "change in church activities" is unclear considering the strong religious belief and background of the Yakima people. It is speculated by the author that perhaps since this event is such a constant factor in the lives of the Yakima people, there is an inability to perceive a change. "Change in recreation" is also an unclear item when compared to the higher ranking of this event on the Miccosukee sample. Perhaps, this is related to the assumption that the Miccosukee tribe is more of a traditional tribe than the Yakima tribe.

\section{GRAND MEAN AND SPREAD DIFFERENCES}

The grand mean of the Yakima sample was 366 out of a possible 1000 as compared to 635 for the Miccosukee sample and 325 for the urban sample. The Yakima rated life event items lower than did the other two samples. The Miccosukee sample rated items higher than did the urban sample. Previous reports indicate that the Yakima sample gave higher ratings than a Black and Mexican American sample.

The grand mean of the Yakima sample, 366, tends to be more compatible to the urban sample with a grand mean of 325 . Although the grand mean is similar, the spread of the first ranked life event item to the last item is more compatible to the Miccosukee sample. The spread of items of the Yakima sample is 386 as compared to 343 for the Miccosukee sample. The spread of first rank item to last item for the urban sample is 830 . Previous reports indicate similarities between the Yakima spread and the spread of items from a Black sample and a Mexican American sample. The grand mean and spread differences would indicate that various groups perceive the amount of readjustment required 
by change events to be different. The spread differences could be interpreted to indicate that the Native American sample are more sensitized to life events whereas the urban sample is more adjusted.

\section{PERCENTAGE OF HIGHEST RANKED ITEM}

The Yakima sample rated "marriage" 5 out of 43 life event items. The Miccosukee sample rated "marriage" 46 out of 50 life event items and the urban sample rated "marriage" 7 out of 43 life event items. Considering the rank order of "marriage" the Yakima sample used a different base line than the other two samples. "Marriage" was considered relatively more stressful for the Yakima sample. Their upper range in scoring life event items is not as high as the other two samples. To further clarify the responses of the three samples, items will be compared as to their relationship with the first item and not the relationship to the item "marriage." The highest ranked life event item of each sample will be considered as a 1000 rating score and every life event item following the first item will be a percentage of the most stressful life event item. For example, on the Yakima sample "death of a partner or spouse" will become 1000 and the second item, "death of a close family member," will be a percentage of the score of the most stressful item. The bars connecting the items are used to signify items intermediate between the three samples. Differences of 100 or greater will be considered. An illustration appears on Table X. By comparing the life event items in this manner, the Yakima and Miccosukee are rela-: tively more compatible in terms of their responses. There is a distinction in scores of the two Native American samples as compared to the urban sample.

\section{FACTOR ANALYSIS}

In order to compare and contrast the three samples, a principal component factor analysis was done on the Yakima data. The data was normalized through a logarithmic transformation and the principal components were rotated for an orthoganal solution by 
TABLE $X$

PERCENTAGE OF HIGHEST RANKED ITEM

\begin{tabular}{|c|c|c|c|}
\hline Item Name & Yakima & Miccosukee & Urban \\
\hline Death of partner or spouse & 1000 & 1000 & 1000 \\
\hline Death of close family member & 996 & 987 & 893 \\
\hline Jail term & 815 & 849 & 863 \\
\hline Death of close friend & 796 & $871=$ & $=506$ \\
\hline Marriage & $786=$ & $-545=$ & $=684$ \\
\hline Loss of home or property & 770 & - & - \\
\hline Separation from partner or spouse & 770 & 783 & $=890$ \\
\hline Change in health of any family member & $752=$ & -839 & -602 \\
\hline Personal injury or illness & 674 & -919 & -726 \\
\hline Pregnancy & 635 & 709 & -547 \\
\hline Teen-age pregnancy occurring in your household & 623 & - & - \\
\hline Fired at work & 619 & - & 643 \\
\hline Change in number of arguments with spouse & $604=$ & -739 & -479 \\
\hline Outstanding personal achievement & 603 & $641=$ & $=383$ \\
\hline Son or daughter leaving home & 601 & - & _397 \\
\hline Foreclosure of loan or mortgage & 594 & - & 410 \\
\hline Household member dropping out of school & 589 & - & - \\
\hline Business adjustment & 586 & $-830-$ & -534 \\
\hline Begin or stop work by husband or wife & 583 & - & - \\
\hline Change in living conditions & 578 & $636=$ & $=342$ \\
\hline Reconciliation with partner or spouse & 557 & - & 616 \\
\hline Gain of new family member & 550 & 643 & 616 \\
\hline
\end{tabular}


TABLE X (Continued)

\begin{tabular}{|c|c|c|c|}
\hline Item Name & Yakima & Miccosukee & Urban \\
\hline Change in responsibilities at work & 540 & $=$ & 397 \\
\hline Retirement & 526 & -632 & 616 \\
\hline Change in eating habits & 525 & 605 & -205 \\
\hline Change in number of family get-togethers & $524=$ & $661=$ & $=205$ \\
\hline Trouble with in-laws & 523 & $586=$ & $=397$ \\
\hline Revision of personal habit & 520 & $=$ & 328 \\
\hline Change in residence & $520=$ & $631-$ & -273 \\
\hline Sexual difficulties & $497=$ & $-792-$ & -534 \\
\hline Change in sleeping habits & $492=$ & -594 & $\underset{219}{2}$ \\
\hline Change to a different line of work & 489 & $-605-$ & -493 \\
\hline Change in working hours and conditions & $481=$ & $-637=$ & $=273$ \\
\hline Taking a short term loan & 480 & - & - \\
\hline Minor violation of law & $468=$ & $=-724=$ & $=150$ \\
\hline $\begin{array}{l}\text { Marriage to a non-Yakima occurring in your } \\
\text { household }\end{array}$ & 458 & - & - \\
\hline Change in social activities & $454=$ & $-670=$ & $=246$ \\
\hline Trouble with boss & 448 & $532=$ & -315 \\
\hline Vacation & 446 & $517-$ & $=178$ \\
\hline $\begin{array}{l}\text { Marriage to male non-Indian occurring in your } \\
\text { household }\end{array}$ & 431 & - & - \\
\hline Begin or stop school & $428-$ & $-565-$ & -356 \\
\hline $\begin{array}{l}\text { Marriage to female non-Indian occurring in your } \\
\text { household }\end{array}$ & 408 & - & - \\
\hline Change in church activities & $400=$ & $-732-$ & $=260$ \\
\hline Change in recreation & $392=$ & $-622-$ & -260 \\
\hline
\end{tabular}


TABLE X (Continued)

\begin{tabular}{|c|c|c|c|}
\hline Item Name & Yakima & Miccosukee & Urban \\
\hline Change in school & 386 & $-516-$ & $=273$ \\
\hline Christmas & - & 528 & -164 \\
\hline Daughter leaving home & - & 770 & - \\
\hline Son leaving home & - & 724 & - \\
\hline Loss of anything you could not make payments on & - & 670 & - \\
\hline Wife beginning or stopping work & - & - & 356 \\
\hline Spouse stopping work outside home & - & 672 & - \\
\hline Spouse starting work outside home & - & 592 & - \\
\hline Major increase in responsibilities at work & - & 676 & - \\
\hline Taking a loan greater than $\$ 5,000$ & - & 791 & - \\
\hline Taking a loan less than $\$ 5,000$ & - & 636 & - \\
\hline Mortgage over $\$ 10,000$ & - & - & 424 \\
\hline Mortgage or loan less than $\$ 10,000$ & - & $\dot{-}$ & 232 \\
\hline Marriage to a non-Indian & - & 870 & - \\
\hline Moving to live in town & - & 816 & - \\
\hline Moving to a different reservation & - & 750 & - \\
\hline Major change in your group of friends & - & 625 & - \\
\hline
\end{tabular}


varimax (Liberman and Frank, 1977). A form factor solution was derived and an arbitrary cut-off by a .45 loading was used for factor description. Results of the factor analysis in responses to items are found to be uninterpretable. Little factor structure was found among the Yakima sample. An assumption is that the Yakima sample was not homogeneous in their attitudes. They were heterogeneous in responses to the life event items, not as constant as the Miccosukee sample. Factor analysis in terms of responses appears in Appendix D. 


\section{CHAPTER V}

\section{CONCLUSION AND RECOMMENDATIONS}

\section{CONCLUSION}

This study investigated two Native American groups, the Yakima Indian Nation and the Miccosukee Tribe of Florida, in their assessment of the adjustment required by certain specified life change events. A culturally modified version of the Social Readjustment Rating Questionnaire was utilized for quantifying the adjustment required by these life events.

In general, responses of the Yakima sample were not as constant as the Miccosukee sample. The Yakima sample appeared to be heterogeneous in their attitudes. A speculation for the heterogenity could be explained by considering the Yakima population as a progressive culture, but yet a culture retaining much of its traditional Indian values. The responses to life event items are indicative of the Yakima sample as being less "Indian" than the Miccosukee group but more "Indian" then the urban group. This would indicate some assimiliation into the white society on the part of the Yakima sample.

Similarities in responses of life event items relating to family and friends between the two Native American samples support the extended family concept among the Native American population. Similarities present the Native American groups as having a close family network and as being a group orientated society.

The lack of spread of life event items on the Yakima sample and the clustering of items toward the top would indicate that the Yakima sample is unable to distinguish "little" changes from "big" changes (Liberman, 1979). The Miccosukee sample also had less of a spread than did the urban sample. It would appear that the Native American samples are more sensitized to change rather than adjusted to change. 
The Social Readjustment Rating Scale was found to be a useful instrument in probing psychological, social and cultural differences between the groups. Similarities were noted in the three groups as were many differences. The extent of the differences and similarities need further exploration.

In summary, a correlation of relative rank ordering of readjustment required by life events was observed by the three groups, but differences in cultures were reflected in the Social Readjustment Rating Scale obtained.

\section{RECOMMENDATIONS FOR FOLLOW-UP}

It is recommended that because the scores are not true interval scores a nonparametric statistical method be used on each of the 33 items subject to an analysis of variance.

This study utilized a 75 percent female and a 25 percent male sample population. The majority of minority studies utilized a larger percentage of female subjects as compared to male subjects. The Black sample utilized a 22 percent male sample and a 78 percent female sample. The Mexican-American sample was 29 percent male and 71 percent female. The Miccosukee sample was represented by a 40 percent male sample population and a 60 percent female sample population. Although the majority of sample populations have been predominately female, attention should be focused on this characteristic when: arriving at sample populations.

It is recommended for further investigation of a Native American group that consideration be made in determining the "Indianism" of the subsample members. This additional data would be useful in explaining heterogeneous responses as they appeared in this study.

In investigating further the readjustment required by specified life event items, it is recommended that the item, "death of a partner or spouse," be given a value of 100 
and participants asked to rank the following items according to the change each item would require. "Death of a partner or spouse" would be used as the highest ranked item, ranking the other items in numerical order according to the change required.

The findings of this study suggest the desirability of extending the investigation further into the cross-cultural area. Any conclusions that can be drawn are tentative in view of the restriction in the samplings from the Native American and urban populations. 


\section{SELECTED REFERENCES}

Bieliauskas, Linas and Strugar, Debra. "Sample Size Characteristics and Scores on the Social Readjustment Rating Scale." Journal of Psychosomatic Research. Vol. 20 (1976): 201-205.

Dohrenwend, Bruce and Dohrenwend, Barbara. "Psychiatric Disorders and Susceptibility to Stress: Reactions to Stress of Varying Magnitude and Varying Origins." Unpublished paper.

Goode, William J. and Hatt, Paul K. Methods In Social Research. (New York: McGraw-Hill Book Co., 1952).

Gregory, Delores. “Abstract." Unpublished paper, 1978.

Harmon, David; Masuda, Minoru; and Holmes, Thomas. "The Social Readjustment Rating Scale: A Cross-Cultural Study of Western Europeans and Americans." Lournal of Psychosomatic Research. Vol. 14 (1970): 391-400.

Hinkle, L.E. "An Investigation of the Reactions Between Life Experience, Personality Characteristics, and General Susceptibility to Illness." Lournal of Psychosomatic Medicine. Vol. 20 (1958): 278.

Holmes, Thomas and Masuda Minoru. "Life Events: Perceptions and Frequencies." Lournal of Psychosomatic Research. Vol. 40 (May, 1978): 236-261.

Holmes, Thomas and Rahe, Richard. "The Social Readjustment Rating Scale." Lournal of Psychosomatic Research. Vol. 11 (1967): 213-218.

Holmes, Thomas. "Life Situations, Emotions, and Disease." Psychosomatics. Vol. 19, No. 12 (1978): 747-754.

Komaroff, Anthony; Masuda; Minoru; and Holmes, Thomas. "The Social Readjustment:. Rating Scale: A Comparative Study of Negro; Mexican and White Americans.": Journal of Psychosomatic Research. Vol. 12 (1968): 121-128.

Liberman, David. Personal Conversation. Portland, Oregon, January 29, 1979.

Liberman, David and Frank, Joel. "The Individual Perceptions of Stressful Life Events: A Comparison of Native American, Rural, and Urban Samples." Paper presented at the South Eastern Psychological Association Meeting, May, 1977, Hollywood, Florida.

Lynch, James. The Broken Heart (New York: Basic Books, Inc., 1977), 61-62, 164-165.

Masuda, Minoru and Holmes, Thomas. "The Social Readjustment Rating Scale: A CrossCultural Study of Japanese and American." Journal of Psychosomatic Research. Vol. 25 (October, 1971): 310-316. 
Paykel, Eugene; Prusoff, Brigitte; and Uhlenhuth, E.H. "Scaling of Life Events." Archs Gen. Psychiat. Vol. 25 (October, 1971): 310-316.

Rahe, Richard; Lundberg, Ulf; Bennett, Linda; and Theorell, Tores. "The Social Readjustment Rating Scale: A comparative Study of Swedes and Americans." Journal of Psychosomatic Research. Vol. 15 (1971): 241-249.

Polansky, N.A. (ed.). Social Work Research (Chicago: The University of Chicago Press, 1962).

Rahe, Richard. "Social Stress and IIIness Onset." Journal of Psychosomatic Research. Vol. 8 (1964): 35.

Rahe, Richard and Arthur, J. "Life Change Patterns Surrounding Illness Experience." Journal of Psychosomatic Research. Vol. 11 (1968): 341.

Rahe, Richard. "Multicultural Correlation of Life Changes Scaling: American, Japanese, Denmark, and Sweden." Journal of Psychosomatic Research. Vol. 13 (1969): 191.

U. S. Public Health Service, Indian Health Service. Portland Area: The People, Place and Program. Crulmon (ed.), Washington: Government Printing Office (1978): 1111-14. 
APPENDIX A

YAKIMA SAMPLE QUESTIONNAIRE 


\section{INDIVIDUAL PERCEPTION OF STRESSFUL_LIEE EVENS}

YOU ARE ASKED TO RATE A SERIES OF. LIFE EVENTS ON A SCALE FROM 0 TO 20 IN TERMS OE THE AMOUNT OF "CHANGE" OR "GETTING USED TO" IT WOULD CAUSE IN YOUR LIFE, THE EVENTS CAN BE VIENED AS HAVING EITHER A NEGATIVE OR POSITIVE IMPACT ON YOUR LIFE, THERE ARE MANY LIFE EVENTS, HHICH WOULD CAUSE A "CiAANGE" IN YOUR LIFE BUT ARE NOT NECESSARILY A "BAD" OR NEGATIVE EXPERIENCE.

MAPRIAGE HAS BEen GIVEN A VALUE. OF "10, As YOU COMPLETE EACH OF THE REMAINING EVENTS THINK TO YOURSELF, "DOES THIS EVENT REQUIRE MOPE OR LESS CHANGE THAN MARRIAGE AND THEN HON MUCH, MORE OR LESS CHANGE?"

IN SELECTING A NUMBER FROM 0 TO 29 TO RATE A LIFE EVENT USE ALL OF YOUR EXPERIENCE IN ARRIVING AT YOUR ANSWER, WHEN. RATING A LIFE EVENT THAT YOU HAVE NOT PERSONALLY EXPERIENCED, CONSIDER WHAT YOU HAVE LEARNED TO BE THE CASE FOR OTHERS.

If YOU DECIDE THE EVENT CAUSES MORE CHANGE THAN MARRIAGE CHOOSE A LARGER NUMBER THAN 10 AND CIRCLE THE NUMBER ON THE SCALE DIRECTLY LNDER THE EVENT. IF YOU DECIDE THE EVENT CAUSES LESS CHANGE THAN MARRIAGE THEN CHOOSE A NUMBER SMALLER THAN IO AND CIRCLE THE NUMBER ON THE SCALE DIRECTLY. UNDER THE EVENT. IF THE EVENT IS EQUAL IN CHANGE OR ADJUSTMENT TO MARRIAGE, CIRCLE THE NUMBER 10 ON THE SCALE. 
INSTRUUCIIONSS: IF YOU DECIDE THE EVENT CAUSES MORE CHANGE THAN MARRIAGE CIRCLE A LARGER NUMBER. THAN 10 ON THE SCALE. IF YOU DECIDE THE EVENT CAUSES LESS OHANGE THAN MARRIAGE THEN CIRCLE A NUMBER SMALER THEN 10 ON THE SCALE. IF THE EVENT IS EQUAL IN CHANGE OR. ADUUSTMENT TO MARRI AGE CIRCLE THE NUMBER 10 ON THE SCALE.

1. MARRIAGe

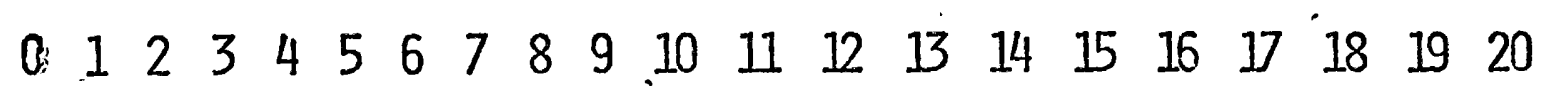

2. TROUBLES WITH BOSS

$\begin{array}{llllllllllllllllllll}0.1 & 2 & 3 & 4 & 5 & 6 & 7 & 8 & 9 & 10 & 11 & 12 & 13 & 14 & 15 & 16 & 17 & 18 & 19 & 20\end{array}$

3. JAIL TERM

$\begin{array}{llllllllllllllllllll}0 & 1.2 & 3 & 4 & 5 & 6 & 7 & 8 & 9 & 10 & 11 & 12 & 13 & 14 & 15 & 16 & 17 & 18 & 19 & 20\end{array}$

4. DEATH OF PARTNER OR SPOUSE

$\begin{array}{lllllllllllllllllllll}0 & 1 & 2 & 3 & 4 & 5 & 6 & 7 & 8 & 9 & 10 & 11 & 12 & 13 & 14 & 15 & 16 & 17 & 18 & 19 & 20\end{array}$

5. Change IN SLEEPING HABITS (MORE OR LESS SLEEP, OR CHANGE IN PART OF DAY WHEN SLEEP)

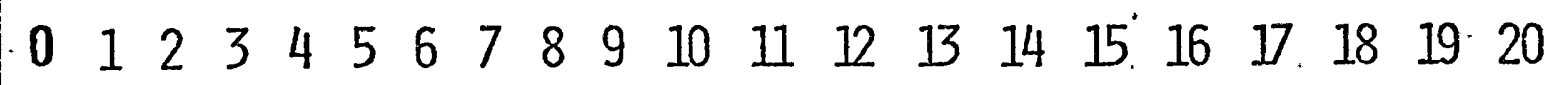

6. DEATH OF A CLOSE FAMILY MEMBER

$\begin{array}{lllllllllllllllllllll}0 & 1 & 2 & 3 & 4 & 5 & 6 & 7 & 8 & 9 & 10 & 11 & 12 & 13 & 14 & 15 & 16 & 17 & 18 & 19 & 20\end{array}$ 
7. Change in EATING HaBitS

$\begin{array}{lllllllllllllllllllll}0 & 1 & 2 & 3 & 4 & 5 & 6 & 7 & 8 & 9 & 10 & 11 & 12 & 13 & 14 & 15 & 16 & 17 & 18 & 19 & 20\end{array}$

8. HOUSEHOLD MEMBER DROPPING OUT OF SCHOOL

$\begin{array}{lllllllllllllllllllll}0 & 1 & 2 & 3 & 4 & 5 & 6 & 7 & 8 & 9 & 10 & 11 & 12 & 13 & 14 & 15 & 16 & 17 & 18 & 19 & 20\end{array}$

9. FORECLOSURE OF MORTGAGE OR LOAN

$\begin{array}{lllllllllllllllllllll}0 & 1 & 2 & 3 & 4 & 5 & 6 & 7 & 8 & 9 & 10 & 11 & 12 & 13 & 14 & 15 & 15 & 17 & 18 & 19 & 20\end{array}$

10. ReVision of PERSONAL habits (DRESS, maNNERS, ETC.)

$\begin{array}{lllllllllllllllllllll}0 & 1 & 2 & 3 & 4 & 5 & 6 & 7 & 8 & 9 & 10 & 11 & 12 & 13 & 14 & 15 & 16 & 17 & 18 & 19 & 23\end{array}$ $\therefore \%$

11. DEATH OF A CLOSE FRIEND

$\begin{array}{lllllllllllllllllllll}0 & 1 & 2 & 3 & 4 & 5 & 6 & 7 & 8 & 9 & 10 & 11 & 12 & 13 & 14 & 15 & 16 & 17 & 18 & 19 & 20\end{array}$

12. Minor violations OF THE LAW

$\begin{array}{llllllllllllllllllllll}0 & 1 & 2 & 3 & 4 & 5 & 6 & 7 & 8 & 9 & 10 & 11 & 12 & 13 & 14 & 15 & 16 & 17 & 18 & 19 & 20 & \vdots\end{array}$

13. OUTSTANDING PERSONAL ACHIEVENENT

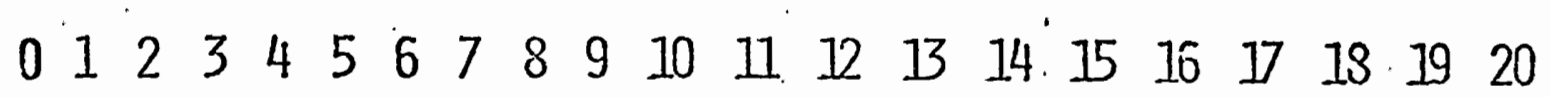

14. PREGNANCY

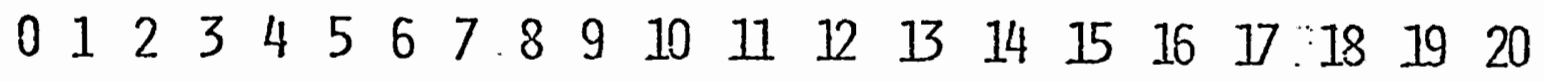


- 15. TEEN-AGE PREGNANCY OCCURRING IN YOUR HOUSEHOLD

$\begin{array}{lllllllllllllllllllll}0 & 1 & 2 & 3 & 4 & 5 & 6 & 7 & 8 & 9 & 10 & 11 & 12 & 13 & 14 & 15 & 16 & 17 & 18 & 19 & 20\end{array}$

16. Change in health of any family menber

$\begin{array}{lllllllllllllllllllll}0 & 1 & 2 & 3 & 4 & 5 & 6 & 7 & 8 & 9 & 10 & 11 & 12 & 13 & 14 & 15 & 16 & 17 & 18 & 19 & 20\end{array}$

17. SEXUAL difficulties

$\begin{array}{lllllllllllllllllllll}0 & 1 & 2.3 & 4 & 5 & 6 & 7 & 8 & 9 & 10 & 11 & 12 & 13 & 14 & 15 & 16 & 17 & 18 & 19 & 20\end{array}$

18. TROUBLE WITH IN-LANS :

$\begin{array}{lllllllllllllllllllll}0 & 1 & 2 & 3 & 4 & 5 & 6 & 7 & 8 & 9 & 10 & 11 & 12 & 13 & 14 & 15 & 16 & 17 & 18 & 19 & 20\end{array}$

19. Change in NuMBer of FaMily get-togetTers

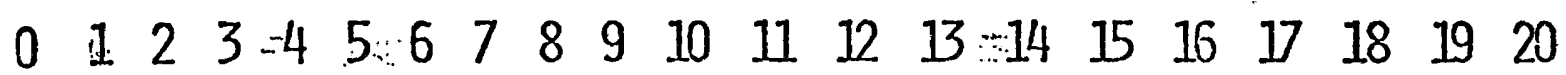

20. Change in Financial STATE

$\begin{array}{lllllllllllllllllllll}0 & 1 & 2 & 3 & 4 & 5 & 6 & 7 & 8 & 9 & 10 & 11 & 12 & 13 & 14 & 15 & 16 & 17 & 18 & 19 & 20\end{array}$

21. GAIN OF NEW FAMILY MENBER

$\begin{array}{lllllllllllllllllllll}0 & 1 & 2 & 3 & 4 & 5 & 6 & 7 & 8 & 9 & 10 & 11 & 12 & 13 & 14 & 15 & 16 & 17 & 18 & 19 & 20\end{array}$

22. CHANGE IN RESIDENCE

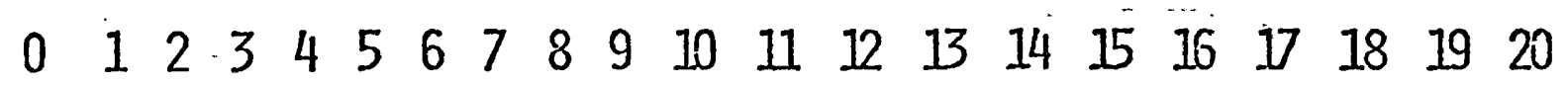


23. SON OR DAUGHTER LeAVing hOMe (MARRiaGe, Attending SCHOOL, etC.)

$\begin{array}{lllllllllllllllllllll}0 & 1 & 2 & 3 & 4 & 5 & 6 & 7 & 8 & 9 & 10 & 11 & 12 & 13 & 14 & 15 & 16 & 17 & 18 & 19 & 20\end{array}$

24. MaRriage to a NON-YaKima occurRing in YOUR household (íF YOU ABE AN ENROLLD YAKIMA)

$\begin{array}{lllllllllllllllllllll}0 & 1 & 2 & 3 & 4 & 5 & 6 & 7 & 8 & 9 & 10 & 11 & 12 & 13 & 14 & 15 & 16 & 17 & 18 & 19 & 20\end{array}$ :

25. SEPARATION FROM PARTINER OR SPOUSE

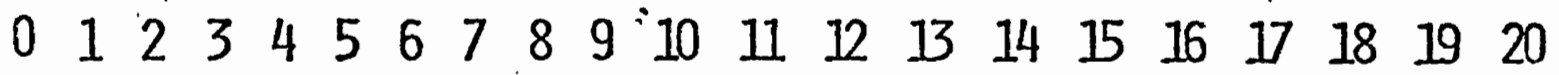

26. CHANGE IN CHURCH ACTIVITIES (MORE OR LESS THAN USUAD

$\begin{array}{lllllllllllllllllllll}0 & 1 & 2 & 3 & 4 & 5 & 6 & 7 & 8 & 9 & 10 & 11 & 12 & 13 & 14 & 15 & 15 & 17 & 18 & 19 & 20\end{array}$ $=\cdots$ 皮.

27. RECONCILIATION WITH PARTNER OR SPOUSE

$\begin{array}{lllllllllllllllllllll}0 & 1 & 2 & 3 & 4 & 5 & 6 & 7 & 8 & 9 & 10 & 11 & 12 & 13 & 14 & 15 & 16 & 17 & 18 & 19 & 20\end{array}$

28. FIRED AT WORK

$\begin{array}{lllllllllllllllllllll}0 & 1 & 2 & 3 & 4 & 5 & 6 & 7 & 8 & 9 & 10 & 11 & 12 & 13 & 14 & 15 & 16 & 17 & 18 & 19 & 20\end{array}$

29. DIVORCE OR SPLIT FROM PARTINER

$\begin{array}{lllllllllllllllllllll}0 & 1 & 2 & 3 & 4 & 5 & 6 & 7 & 8 & 9 & 10 & 11 & 12 & 13 & 14 & 15 & 16 & 17 & 18 & 19 & 20\end{array}$

30. CHANGE TO A DIFFERENT LINE OF WORK

$\begin{array}{lllllllllllllllllllll}0 & 1 & 2 & 3 & 4 & 5 & 6 & 7 & 8 & 9 & 10 & 11 & 12 & 13 & 14 & 15 & 16 & 17 & 18 & 19 & 20\end{array}$ 
31. ChANGE IN NUMBER OF ARGUNENTS WITH SPOUSE (MORE OR FEVER)

$\begin{array}{lllllllllllllllllllll}0 & 1 & 2 & 3 & 4 & 5 & 6 & 7 & 8 & 9 & 10 & 11 & 12 & 13 & 14 & 15 & 16 & 17 & 18 & 19 & 20 .\end{array}$

32. CHANGE IN RESPONSIBILITIES AT WORK

$\begin{array}{lllllllllllllllllllll}0 & 1 & 2 & 3 & 4 & 5 & 6 & 7 & 8 & 9 & 10 & 11 & 12 & 13 & 14 & 15 & 16 & 17 & 18 & 19 & 20\end{array}$

33. BEGIN OR STOP WORK BY HUSBAND OR WIFE

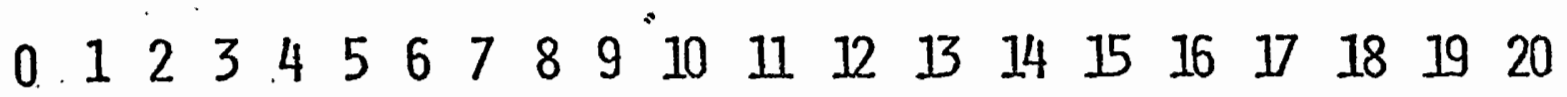

34. GHANGE IN WORKING HOURS OR CONDITIONS

$\begin{array}{lllllllllllllllllllll}0 & 1 & 2 & 3 & 4 & 5 & 6 & 7 & 8 & 9 & 10 & 11 & 12 & 13 & 14 & 15 & 16 & 17 & 18 & 19 & 20\end{array}$ $\div$

35. Marriage to Male NaN-Indians OCCURRing in YOUR HOUSEHOLD

$\begin{array}{lllllllllllllllllllll}0 & 1 & 2 & 3 & 4 & 5 & 6 & 7 & 8 & 9 & 10 & 11 & 12 & 13 & 14 & 15 & 16 & 17 & 18 & 19 & 20\end{array}$

36. ChANGE IN RECREATION

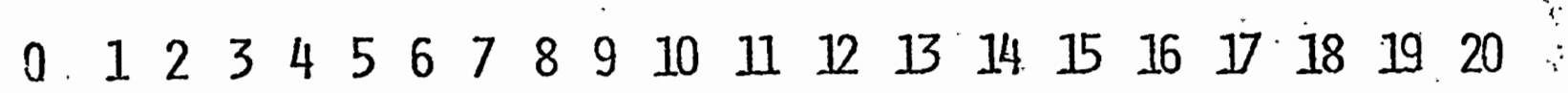

37. TAKING A SHORT TERM LOAN

$\begin{array}{lllllllllllllllllllll}0 & 1 & 2 & 3 & 4 & 5 & 6 & 7 & 8 & 9 & 10 & 11 & 12 & 13 & 14 & 15 & 16 & 17 & 18 & 19 & 20\end{array}$

38. PeRsonal inJuRY OR ILINESS

$\begin{array}{lllllllllllllllllllll}0 & 1 & 2 & 3 & 4 & 5 & 6 & 7 & 8 & 9 & 10 & 11 & 12 & 13 & 14 & 15 & 16 & 17 & 18 & 19 & 20\end{array}$ 
39. BUSINESS ADJUSTNENT (REORGANIZATION, BANKRUPTCY, ETC.)

$\begin{array}{lllllllllllllllllllll}0 & 1 & 2 & 3 & 4 & 5 & 6 & 7 & 8 & 9 & 10 & 11 & 12 & 13 & 14 & 15 & 16 & 17 & 18 & 19 & 20\end{array}$

40. CHANGe IN SOCIAL AVtivities

$\begin{array}{lllllllllllllllllllll}0 & 1 & 2 & 3 & 4 & 5 & 6 & 7 & 8 & 9 & 10 & 11 & 12 & 13 & 14 & 15 & 16 & 17 & 18 & 19 & 20\end{array}$

47. Marriage to female nON-INDian occurRing in your household

$\begin{array}{lllllllllllllllllllll}0 & 1 & 2 & 3 & 4 & 5 & 6 & 7 & 8 & 9 & 10 & 11 & 12 & 13 & 14 & 15 & 16 & 17 & 18 & 19 & 20\end{array}$

42. Change in Living conditions (buibing nen home, Remodeling, Deterioation OF HONE OR NEIGHBORHOOD, ETC, )

$\begin{array}{lllllllllllllllllllll}0 & 1 & 2 & 3 & 4 & 5 & 6 & 7 & 8 & 9 & 10 & 11 & 12 & 13 & 14 & 15 & 16 & 17 & 18 & 19 & 20\end{array}$

43. Retirement

$\begin{array}{lllllllllllllllllllll}0 & 1 & 2 & 3 & 4 & 5 & 6 & 7 & 8 & 9 & 10 & 11 & 12 & 13 & 14 & 15 & 16 & 17 & 18 & 19 & 20\end{array}$

44. VACATION

$\begin{array}{llllllllllllllllllllll}0 & 1 & 2 & 3 & 4 & 5 & 6 & 7 & 8 & 9 & 10 & 11 & 12 & 13 & 14 & 15 & 16 & 17 & 18 & 19 & 20 & \vdots\end{array}$

45. BEGIN OR END SCHOOL:

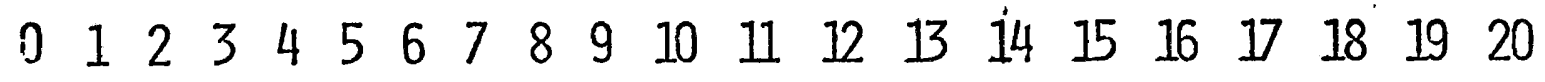

46. LOSS OF HOME OR PROPERTY

$\begin{array}{lllllllllllllllllllll}0 & 1 & 2 & 3 & 4 & 5 & 6 & 7 & 8 & 9 & 10 & 11 & 12 & 13 & 14 & 15 & 16 & 17 & 18 & 19 & 20\end{array}$ 
47. Change in SChOOLS

$\begin{array}{lllllllllllllllllllll}0 & 1 & 2 & 3 & 4 & 5 & 6 & 7 & 8 & 9 & 10 & 11 & 12 & 13 & 14 & 15 & 16 & 17 & 18 & 19 & 20\end{array}$ 


\section{DECLARATION OF INFORMED CONSENT}

The nature and purpose of this study has been fully explained to me. I understand that I will be providing some personal information in an interview in which questionnaires will be used. I understand further that my name will not be used under any circumstances; and that the strictest confidentiality will be observed at all times.

Name

Signature

Date

Witnessed 


\section{APPENDIX B}

\section{OUTLINE OF TRAINING SESSION}


THE INTERVIEW PROCESS

PARTS OF....

1. Making Contact with the Person to be Interviewed.

2. Introducing the Interview.

3. Asking the questions.

4. Recording the Answers.

5. Closing the Interview.

A BREAKDOWN of INTERVIEWER DO's and DON'TS by INTERVIEW PART

1. Making Contact with the Person to be Interviewed

a. After you knock on the door and someone answers, ask for the person you are to interview. Do this before you do anything else in order to make certain you're interviewing the right person.

b. Politely request a quiet place where you'll be alone.

c. If it is impossible for you to be alone with the respondent, accept the - situation and make the best of it.

2. Introducing the Interview

a. Don't memorize or read the introduction.

b. Be sure to include all of the things that are present in the introduction but don't memorize it.

c. Give all respondents similar instructions as much as possible.

d. Be courteous and businesslike at all times.

e. Oress in the manner most often seen in the survey area.

3. Asking the questions

The RULE of THUMB for this part of the interviewing process is--yoU MUST ATTEMPT TO CONTROL YOUR BEHAVIOR TO KEEP FROM INFLUENCING THE ANSWERS, that is BE NEUTRAL. If you don't, the survey will not provide true information from the respondents but will, instead, reflect your own attitudes and opinions.

a. Learn to read the questions smoothly.

b. Read the questions in the same wording and the same order as presented on the questionnaire.

c. If a question is potentially embarrassing for you or the respondent don't change your facial expression, hesitate, on stumble over the question. 
d. Don't show surprise, approval, or disapproval at any answer.

e. Always appear interested in what the respondent has to say.

6. Adjust the pace of the interview to the respondent.

9. Probing is defined as a repeat of the question in some form in order to obtain more information. Because it involves revising the question slightly possible interviewer error is introduced las each interviewer would revise the question differently). Thus the RULE of THUMB is-USE PROBING TECHNIQUES SPARINGLY-ONLY WHEN ABSOLUTELY NECESSARY. In the interview you are about to deliver there are only one or two questions that may require some probing.

1. If a respondent does not appear to understand a question when you ask it, repeat it exactly as it is written. If

WHEN AND

HOW TO

PROBE

$-\quad \cdots$ the respondent still seems unable to. understand the question then rephrase the question in words you think the respondent will understand.

2. If the respondent's answer is unclear. irrelevant, or incomplete, then rephrase the question.

3. Be sure to record any probes on the questionnaire.

4. Recording the Answers

a. Write legibly.

b. Record the answers as soon as the respondent gives them.

c. Be sure you have recorded the responses in the correct place:

d. 'On' any open-ended questions (there are very few in this questionnaire) write the respondent's answers exactly as he/she said it.

e. Some sources of ERROR to be avare of are:

1. Fatigue of the interviewer.

2. Conducting the interview too rapidly--here, you might record answers while asking the next question. This is BAD.

3. Failure to check over questionnaire before leaving.

4. Faifure to record answer in correct place.

5. Failure to lister to respondent.

6. Always use a pencil.

9. Account for any non-responses.

h. Record in DETAIL any interruptions occurring during the interview, any important comments made by the respondent, and any significant events occurring during the interview. 
5. closing the Interview

a. Review the questionnaire in the presence of the respondent and ask any. incomplete questions.

b. Ask respondent if he/she wants more information.

c. Thank the respondent.

HOW tò HANDLE REFUSALS On ABSENCE of RESPONOENT

1. Preventive Measures for Avoiding Refusals.

a. After knocking on the door, stand where you can easily be seen.

b. Wear clothing most often seen in the area.

c. Be polite and pleasant.

d. Keep your promise that the interview is confidential.

e. Behave in a manner acceptable to the community.

6. A good introduction will usually lead to cooperation of the respondent.

2. If After Your Introduction You Are Refused, Accept This Response and Try to work with Their Excuse to Obtain an Interview.

a. If the respondent says he/she doesn't have the time to do an interview, ask when it would be most convenient for you to return.

b. Appeal to the respondent's sense of civic duty.

3. I6. After an Attempt to Encourage the Respondent to Participate, He/She Still Refuses, Leave the Respondent with Some Polite Statement.

4. The Best Preventive Measure for Avoiding "not at home" Calls is to call on Respondents at PRIME TIME.

5. If the Respondent is Not Home when You Call, a "call back" Must be Made at a Different Time.

6. If unsuccessful in the First "call back" Check with the Neighbors to Find out when the Respondent Will be Home.

7. Under Certain Circumstances it is Best NOT to Attempt an Interview (for example, during a family argument or a medical emergencyl.

8. Always Record Refusals, Call Backs, and Any Other Unusual Circumstances. 
APPENDIX C

\section{LETTER SENT TO PARTICIPANTS}




\section{Yakima Indian Nation}

POST OFFICE BOX 632

TOPPENISH, WASHINGTON -98948

July 26,1978 .

TO WHOM IT MAY CONCERN:

This letter is to tell you that you will be contacted in the near future and asked to answer a questionnaire about yourself and your family.

You are one of approximately 300 Indians living on the Yakima Reservation (tribal members) selected at random to participate in the study. The 300 names are representative of people over eighteen years of age. The names of the 300 people were obtained from tribal rolls and Indian Health Service.

The study is being conducted as a cooperative effort of the Yakima Tribe and Indian Health Service to improve the delivery of mental health and social services. Through your cooperation in answering the questionnaire more can be learned about the Yakima Tribe, and other Indians living on the reservation, their illnesses and other aspects of their lives. The information will be used to assist in solving these problems more easily and to be able to prevent many problems before they arise.....

Your name will not be used in any way. It will NOT be on the questionnaire. Everything is strictly confidential.

In answering the questionnaire, please note, there are no right or wrong answers. Everyone has experienced difficulties at one time or another and we all have our own way of dealing with our problems. The fact that your name was chosen does not nean that you have problems but that it was picked by chance.

Your cooperation in this survey is essential. The Yakima Indian Nation and Indian Health Service would appreciate your assistance in gathering this information. "This information will be used in the final planning of tribal program already being developed.

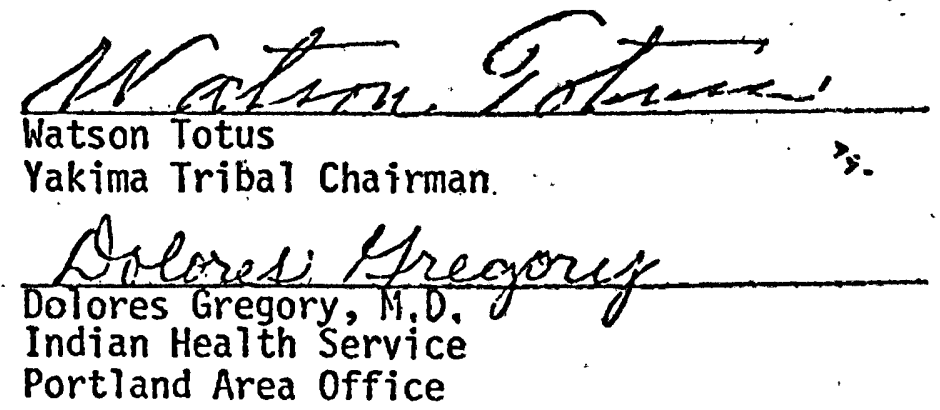


APPENDIX D

FACTOR ANALYSIS IN TERMS OF RESPONSES 


\section{FACTOR I}

\begin{tabular}{ll}
\hline Loading & Item Name \\
\hline .54971 & Death of partner or spouse \\
.58009 & Death of a close family member \\
.45356 & Change in eating habits \\
.63667 & Household member dropping out of school \\
.62375 & Foreclosure of mortgage or loan \\
.65588 & Revision of personal habits \\
.64472 & Death of a close friend \\
.56271 & Minor violations of law \\
.60555 & Outstanding personal achievement \\
.59360 & Pregnancy \\
.69336 & Teen-age pregnancy occurring in your household \\
.72819 & Change in health of any family member \\
.62377 & Sexual difficulties \\
.60251 & Trouble with in-laws \\
.54542 & Change in number of family get-togethers \\
.69877 & Change in financial state \\
.60752 & Gain of new family member \\
.58115 & Change in residence \\
.55318 & Son or daughter leaving home \\
.68522 & Marriage to a non-Yakima occurring in your household \\
.68431 & Separation from partner or spouse \\
.59772 & Change in church activities \\
\hline .71776 & Reconciliation with partner or spouse \\
\hline
\end{tabular}


FACTOR I (Continued)

\begin{tabular}{|c|c|}
\hline Loading & Item Name \\
\hline .77139 & Divorce or split from partner \\
\hline .75141 & Change to a different line of work \\
\hline .57866 & Change in number of arguments with spouse \\
\hline .76585 & Change in responsibilities at work \\
\hline .75621 & Begin or stop work by husband or wife \\
\hline .73588 & Change in working hours and conditions \\
\hline .75429 & Marriage to male non-Indian occurring in your household \\
\hline .68404 & Change in recreation \\
\hline .57875 & Taking a short term loan \\
\hline .70601 & Personal injury or illness \\
\hline .79789 & Business adjustment \\
\hline .70682 & Change in social activities \\
\hline .73741 & Marriage to female non-Indian occurring in your household \\
\hline .65304 & Change in living conditions. \\
\hline .72307 & Retirement \\
\hline .63149 & Vacation \\
\hline .74158 & Begin or end school \\
\hline .73718 & Loss of home or property \\
\hline .69453 & Change in schools \\
\hline
\end{tabular}


FACTOR II

Loading Item Name

.45611 Change in sleeping habits

$.45356 \quad$ Change in eating habits

-.45920 Loss of home or property

FACTOR III

$\therefore$

Loading Item Name

.49671 Jail term

.48962 Minor violations of law

*ALL LOADINGS LESS THAN .45 ARE OMITTED 